\title{
Looking Into Community Pharmacy: Identifying Effective Communication Skills in Pharmacist-Patient Consultations.
}

Hargie, O., Morrow, N., \& Woodman, C. (1993). Looking Into Community Pharmacy: Identifying Effective Communication Skills in Pharmacist-Patient Consultations. Ulster University.

Link to publication record in Ulster University Research Portal

Publication Status:

Published (in print/issue): 01/06/1993

\section{Document Version}

Publisher's PDF, also known as Version of record

\section{General rights}

Copyright for the publications made accessible via Ulster University's Research Portal is retained by the author(s) and / or other copyright owners and it is a condition of accessing these publications that users recognise and abide by the legal requirements associated with these rights.

\section{Take down policy}

The Research Portal is Ulster University's institutional repository that provides access to Ulster's research outputs. Every effort has been made to ensure that content in the Research Portal does not infringe any person's rights, or applicable UK laws. If you discover content in the Research Portal that you believe breaches copyright or violates any law, please contact pure-support@ulster.ac.uk. 


\section{Looking Into Community Pharmacy*}

Identifying Effective Communication Skills in

Pharmacist-Patient Consultations

Owen Hargie, Norman Morrow and Catherine Woodman

*This Report was published in summary form as:

Hargie, O, Morrow, N. \& Woodman, C. (2000) 'Pharmacists' evaluation of key communication skills in practice', Patient Education and Counseling, 39, 61-70. 


\title{
A joint publication by
}

\section{School of Communication, University of Ulster, Jordanstown and School of Pharmacy, The Queen's University, Belfast}

\author{
Printed in Northern Ireland by \\ University of Ulster, Jordanstown, BT37 0QB.
}

All rights reserved. No part of this publication may be reproduced, stored in a retrieval system, or transmitted in any form or by any means, electronic, mechanical, photocopying, recording or otherwise, without permission in writing from the authors. 


\section{CONTENTS}

Acknowledgements

1. Chapter 1: Background to the Study

2. Chapter 2: Methods and Procedures

3. Chapter 3: Results

4. Chapter 4: Discussion

Bibliography

88

Appendices

98 


\section{Acknowledgements}

Few research projects are completed without the support of many and this one is no exception. We are grateful to the Leverhulme Trade Charities Trust who provided the funding which made this research investigation possible. We would also wish to acknowledge all the support provided by the University of Ulster and the Queen's University of Belfast (QUB) throughout the two years of the research.

In particular we would like to acknowledge the help received from the following staff of the University of Ulster at Jordanstown: Alastair Gilmore, Chief Technician of the Faculty of Social and Health Sciences, for all his help and advice on technical matters; Joe O'Neill for his technical assistance and enduring good nature during the many hours spent videorecording in pharmacies; Philip Burch for his time, skill and patience in producing, often at short notice, the necessary graphic materials; and the staff of the Education and Technical Unit for all their assistance during the long days of video editing. We owe a very real debt of gratitude to Fidelma Haffey, research assistant in the Department of Communication at UUJ, who devoted a great deal of time and expertise to the video editing and who also contributed ideas about the research project itself and always with such infectious good humour. Thanks are also due to Mary Duffy, research assistant in the Department of Communication at UUJ, for her help at the stage of analysis of videotapes.

We are equally appreciative of all the support received from the staff of the School of Pharmacy, QUB, especially that from Mr Alan Robinson for his goodwill during the stages of data analysis and write up, and Ms Lesley Crawford for her constant and invaluable help during the second phase of the project.

Finally, we are indebted to the 15 community pharmacists who participated in the study. They not only gave so generously of their time and hospitality during the long hours of recording, but shared their wisdom and experience during the sometimes exhausting evening periods of tape analysis and skill categorisation. An essential part of this research was that all pharmacists and patients would remain anonymous, so to all these unsung individuals we here express our sincere gratitude. 


\section{Chapter 1: Background to the Study}

\section{Communication and Health Care}

The last decade has witnessed an ever increasing appreciation of the role of communication in the delivery of health care and of the importance of the interpersonal skills of health professionals. The former reliance upon a medical model of care has been replaced by a more patient-centred approach in which the relationship with patients is seen as an important part of treatment (Stewart and Roter, 1989). The impetus to improve communication has also been stimulated by a more consumerist attitude on the part of patients who are increasingly prepared to question services and indeed treatments (Armstrong, 1991; Skipper, 1992). Furthermore, within the U.K. the recently published Patients' Charter (Department of Health, 1991) now officially details what members of the public are entitled to by way of health care provision.

As Smith and Bass (1982) have pointed out: "Much of health care is communication centred. As a health professional you give directions, offer reassurances, provide consolation, commiserate, interpret, receive information and carry out directions. The more effectively and efficiently you learn to communicate, the more accomplished you become in fulfilling your health service role." It is hardly surprising therefore that in 1989 a journal entitled Health Communication was introduced specifically to study this dimension of care. Indeed, Dickson et al. (1989) suggest that health professionals may be regarded as a sub-set of what has been termed by Ellis and Whittington (1981) 'the interpersonal professions' for whom communication is an integral and essential component of the professional role.

Within pharmacy there is a growing recognition of the changing image of community pharmacists, resulting in suggestions that the time afforded by the shift from their traditional role of compounder of medicines to dispenser of pre-packed preparations should be reallocated towards activities such as patient counselling and health education (Smith, 1986; Tapster, 1987; Morrow and Hargie, 1992). Moreover, a consideration of the legal obligation of pharmacists to provide adequate drug information for patients, suggests that their professional role as adviser / educator can no longer be regarded as an option within community pharmacy practice (Brushwood and Simonsmeier, 1988). Several publications have called for greater communication between pharmacist and patient (Miller, 1981; Gravett, 1985; McKenzie, 1986), yet few attempt to define what constitutes effective communication, either in general terms or within the context of community pharmacy. 


\section{Communication Defined}

The study of communication has developed at a rapid pace within the U.K. over the past decade. Indeed, Hargie (1992) has illustrated how communication is now widely regarded as a social science discipline in its own right, akin to psychology or sociology, and he defines communication in this sense as: "The scientific study of the production, processing and effects of signal and symbol systems used by humans to send and receive messages." At the same time, there tends to be some confusion about the exact meaning of terms such as communication and communications, since these are employed to represent a wide range of differing concepts. For this reason Ellis and Beattie (1986) refer to communication as a 'fuzzy' concept whose boundaries are blurred and uncertain.

Dickson et al. (1989) highlight a number of facets often used to delineate interpersonal communication. They point out that reference is frequently made to its inevitability in the belief that where two individuals are present and aware of each other, communication is ipso facto taking place. In line with this view Watzlawick et al. (1967) stated that "...no matter how one may try, one cannot not communicate. Activity or inactivity, words or silences all have message value: they influence others and these others, in turn, cannot not respond to these communications and are thus themselves communicating." Nonetheless, the inevitability of communication is not without challenge. Gahagan (1984) makes the distinction between information and communication, suggesting that the latter is an intentional act involving the deliberate encoding, transmission and decoding of messages as opposed to other actions, such as blushing, which is regarded as expressive rather than communicative. In keeping with this argument, informing is inevitable, but not communication. Therefore, as emphasised by Dickson et al. (1989), the health professional needs to be aware of the totality of the detail being provided; to what is said, how it is said and what else is happening while it is being said, in order for effective communication to occur.

Within pharmacy, communication has also been variously defined. In his consideration of the community pharmacy context, Kitching (1986) refers to the "complex interaction process involving the encoding and transmission of a message with a meaning attached to it by some channel from one person to another". He continues: "The recipient of a message indicates, by verbal or nonverbal feedback, whether the message has been received, decoded and understood. The feedback allows the original sender to respond in turn and adjust subsequent input (such that) the process involves understanding, meaning and responsiveness". In similar vein, Whitney (1988) describes communication as a "two-way process - transmitting 
and receiving", while Morrow and Hargie (1986) refer to communication in terms of "the ability of the individual to interact effectively with others".

In the light of this latter perspective, the question arises as to whether competence in communication can be achieved and adequately assessed. It is not surprising that this issue has generated considerable opinion given that: "Competence is an issue both perennial and fundamental to the study of communication" (Spitzberg and Cupach, 1984). In definitions of interpersonal competence two core features tend to be predominant, namely knowledge and skill. The following are typical of such definitions:

"..competence has two dimensions - knowledge and skills. Knowledge includes our awareness and understanding of the numerous variables which affect human relationships. Skills involve the ability to pragmatically apply, consciously or even unconsciously, our knowledge." (Konsky and Murdock, 1980).

"Communication competence focuses on the individual's ability and skill, which necessarily includes both knowledge of the social communication rules and the wherewithal to perform in an appropriate manner." (Wiemann and Backlund, 1980).

Dickson et al. (1989) highlight other important features of communication competence. According to them, competent communication is both culturally and circumstantially determined, such that what constitutes competent social behaviour within one context may be unacceptable in another. In the same way, assessment of the competence of a particular interaction must consider the opinion or world view of the 'other'. McCroskey (1984) summarises communication competence as requiring that the individual has a repertoire of communication skills, has a predisposition towards communicating with others and finally, has the opportunity to communicate competently.

Given the above constituents of competent communication, it is evident that a core defining feature of competence is skill to perform the task effectively. However, the definition of interpersonal communication as skill has been the focus of considerable debate with a wide variety of alternative definitions being proffered in the literature (Hargie, 1986). Following a comprehensive review of these definitions and a subsequent analysis of the nature of skill, Hargie (1986) defined interpersonal skill as "a set of goal-directed, inter-related, situationally appropriate social behaviours which can be learned and which are under the control of the individual". In order to appreciate the relevance of this definition it is useful to consider the six components of skilled performance contained within it and examine their relevance to community pharmacy. 
1. Goal-directed. Skilled behaviour is purposeful and intentional and is carried out in order to achieve goals. These goals may not always be consciously pursued and indeed one feature of all skilled performance is that goals are subconscious. The skilled car driver is not consciously aware of goals when driving and does not have to consciously think 'I want to turn left therefore I must move the steering wheel'. Likewise the skilled pharmacist does not have to consciously think 'I want to find out if the patient has understood therefore I must ask a relevant question'.

2. Inter-related. Social skill involves elements of verbal and nonverbal communication which are closely synchronized in order to bring about a desired consequence. For example, the pharmacist's guggles ( $\mathrm{hh} \mathrm{hu,} \mathrm{hm} \mathrm{hm}$ ), headnods and eye contact should be co-ordinated in such a way as to encourage the patient to continue talking, thereby providing important additional information about their situation

3. Appropriate. To be skilled, social behaviour must be appropriate to the situation. A simple example of this is that the pharmacist may wear pyjamas to bed but should not wear them in the pharmacy!

4. Behaviours. This is really the essence of skill. We judge whether people are socially skilled or not based upon how they actually behave.

5. Learned. For the most part, behaviours displayed in the social context are learned by a process of modelling or imitating the performance of significant others. Thus a preregistration pharmacist is likely to observe and copy the styles, strategies and behaviour of experienced practitioners working in the same environment. Given that skills are learned, it is therefore important to identify effective pharmacist performance and teach the relevant skills to pharmacy trainees.

6. Control. Skilful communication demands that individuals have control over their behaviour and learn not just what the appropriate behaviours are but also how and when to use them. Thus an important dimension of skill relates to the timing of certain aspects of performance. For example, the pharmacist who will not be pressurised into supplying an antibiotic without a prescription may allow considerable gaps in the flow of conversation to continue in order to convey assertiveness.

\section{Research into Practitioner-Patient Communication}


In the light of the above definition the need to address the issues of communication within the health professions becomes evident. For instance, Eastwood (1985) in analysing nursepatient communication highlighted a need within the nursing profession to improve communication performance, to investigate the needs of patients, particularly in respect to reducing anxiety and to address the issue of patients' social needs. In the same way, research within dentistry (Furnham, 1983) suggests that patients seek certain attributes in a dentist, namely the ability to perceive and cope with patient anxiety, to establish and maintain rapport and finally, to inform patients and provide explanations.

More generally, previous research into patient-practitioner communication, summarised by Dickson et al. (1989), provides insight into the nature of the patient-practitioner relationship, the issues of patient compliance and benefits of effective communication. These authors report research findings which indicate that the greatest source of patient dissatisfaction with medical care is in relation to the amount and form of information received and that patient compliance with medical advice is associated with their perceptions regarding the credibility of information received, their evaluation of costs versus benefits of prescribed treatment regimes, and medication knowledge. As Ley (1988) points out: "Patients' levels of satisfaction with various aspects of the care they receive are important for two main reasons. The first of these is that patient satisfaction is a desirable goal in its own right. The second....is that patient satisfaction is an important determinant of patients' compliance with advice."

The relationship between patient satisfaction and treatment compliance has been empirically supported (Korsch et al., 1968; Becker and Maiman, 1975; Becker and Rosenstock, 1984), revealing that patients often forget or fail to understand what information they have been given. This has been shown to be related to the use of inappropriately 'pitched' language or terminology (Becker and Maiman, 1980; Ley, 1982), patients' lack of elementary medical knowledge (Ley, 1977a) and reluctance to ask their doctor for additional information (Maguire, 1984). While Ley (1977b) found that, following consultations, patients forgot between 30 and $50 \%$ of information, Cassata (1978) has observed that although age and intelligence were not associated with information recall, patients who were moderately anxious recalled the most information as did those with increased medical knowledge. Cassata also found that patients remembered what they were told at the beginning of the consultation and also what they considered to be most important. However, the greater the amount of information given the more was forgotten, with instructions and advice being more likely to be forgotten than other information. In summarising the relevant research findings, Morrow et al. (1993) list the key findings as follows: 
* Patients tend to be dissatisfied with advice and information received.

* There is poor compliance with advice given.

* Patient satisfaction and compliance are related.

* There is often failure among patients to remember or understand what they have been told.

* Patient understanding and recall can be improved through better instructional technique.

* Practitioners often ignore or fail to fully attend to the psychosocial needs of patients, which in turn leads to alienation from, and dissatisfaction with, medical care.

Dickson et al. (1989), from their review of research, conclude that patient understanding and recall may be improved (thereby enhancing their satisfaction and compliance) through attending to the following points.

1. Patients remember best the first instructions presented.

2. Emphasised instructions are better recalled.

3. Repetition of instruction enhances recall.

4. The fewer the instructions given, the greater proportion of information remembered.

5. Simplification of information enhances recall.

\section{The Pharmacy Context}

The proliferation of research findings into practitioner-patient communication clearly highlights the need for CST in pharmacy and this need has been expressed within the profession (Hargie and Morrow, 1986a). The relevance of individual communication skills in retail pharmacy has been considered (Evison and Veitch, 1985; Kitching 1986; Minty, 1986) and it has been noted that, as the last member of the health care team to have contact with patients before they become independent in the administration of their medication, the pharmacist is in the ideal situation to reinforce any previously presented information and to answer questions (Watts, 1989). However, their success in so doing is dependent upon their ability to communicate effectively.

This responsibility of the pharmacist to provide medication-specific information is supported by Balon (1986) who argued that treatment compliance may be enhanced by providing patient-specific directions that are related to real time events. Alternatively, Gossel (1982) highlighted the issues of attending to the use of language and the provision of a suitable counselling environment, while Beardsley (1986) emphasised the need to establish wider communication links in cases such as terminal illness, in which it may be equally necessary 
to interact with the patient's family. When dealing with serious illness Kilwein (1987) stressed both the need for compassion when interacting with the patient (as indicated by the pharmacist's appropriate verbal and nonverbal communication) and the importance for the pharmacist to be aware of personal feelings and how these might be communicated to the patient. This he feels may be as personally beneficial to the pharmacist as to the patient, concluding that "as pharmacists become more involved with patients as people they are less likely to experience career burnout".

This aspect of personal involvement is particularly pertinent in caring for the terminally ill patient where pharmacists must be able and willing to address the very evident emotional concerns. Inevitably this will mean that the issues of death and dying will have to be addressed. This approach is advocated by Okolo and McReynolds (1987) whose consideration of the pharmacist's role in counselling the terminally ill led them to remark that "for pharmacists to adequately serve the needs of dying patients, they should not only provide their expertise on drug therapy to alleviate pain but also be prepared to counsel the patient on death and dying", and yet "training programmes have provided little education on handling the subjects of death and dying". As a result, these authors comment that many health professionals have ineffective communication skills when working with the dying patient. Okolo and McReynolds conclude that "developing an understanding of the needs of the terminally ill and skills of communication will....help overcome these deficiencies".

This view is reinforced by the earlier work of Du Vall and Lash (1984), who contend that the pharmacists are in a unique position to counsel the oncology patient because of their accessibility and further argue that: "when we provide information to cancer patients we must remember that each patient is an individual; we owe him our best efforts and our honesty. Nonverbal behaviour of the pharmacist should be consistent with verbal expressions of empathy, interest and concern. Direct eye contact is important and a reassuring pat on the shoulder can put a nervous patient at ease." However, an investigation of the provision of death education as part of the undergraduate pharmacy curriculum in the U.S.A. revealed that the majority of graduates were without adequate education in the counselling of the terminally ill patient (Sumner et al., 1987). Thus, the need to investigate the pharmacist's appropriate use of specific communication skills in response to the issues of death and dying becomes evident.

In relation to the elderly patient, Campbell (1981), in an analysis of the issues and priorities for research in geriatric medicine, summarised the main needs of elderly patients within the pharmacy context as being threefold: (i) the review of drug use; (ii) the pharmacist's detailed and current understanding of pharmotherapeutic knowledge; and (iii) an appreciation of the 
psychosocial needs of the elderly. Others have made specific reference to problems such as medication non-compliance and difficulty in following treatment regimes (Cooper, 1978; Ascoine et al., 1980; Lamy and Beardsley, 1982).

Portnoy (1985) emphasised the communication issues involved in interacting with the elderly patient, giving due consideration to the impact of sensory loss upon effective communication with this group of patients, while concurrently underlining the extent to which communication may be enhanced through the pharmacist's building of rapport and devoting adequate time to the consultation, thereby engendering a relationship of trust and respect. She concluded that "by increasing their awareness and knowledge of how to communicate with older patients, pharmacists can more adequately understand and service the growing needs of this group". Yet to date, no study has investigated the nature of communication skills essential to effective interaction with the elderly population.

During the last 25 years pharmacy practice has, in fact, become markedly differentiated, with pharmacists seeking careers, not only in the traditional areas of hospital and community practice, but in science, in the pharmaceutical industry, in management, in clinical pharmacy, in business and in research (Brodie, 1982). Change has not only occurred at the global level but also at grass roots level where, for example, particularly in community practice, timehonoured compounding skills have been taken over by technological advances. In addition, the discovery of new drugs, the complexity of therapeutics, the information explosion, the emergence of biopharmaceutics and pharmacokinetics and the growth of health education services, rank among the factors influencing the change from a 'product'- oriented service to a 'patient' - oriented service. Indeed, the clinical pharmacy movement has illustrated this orientation in pharmacy practice (Smith, 1983).

Pharmaceutical education needs to change in response to these new movements, yet in the early 80 's there was evidence to suggest a widening of the gap between education and practice (Mija, 1980; Weaver, 1980; Fisher and Morris, 1983). Although steps have taken place during the last decade to narrow this gap (Dickson et al., 1989), there remains a need to identify those areas within the curriculum which are relevant and important to practice and those which are not and to identify areas which currently need to be included to meet the demands of an expanding role.

Traditionally, the behavioural and social sciences have not played a very important role in the majority of pharmacy schools, in spite of the fact that "hanging onto every bottle of medicine there is a patient" (Finkelstein, 1981). In effect, pharmacy education has majored on the cognitive and technical or manipulative skills required by the profession at the 
expense of social or communication skills training. At best it has been assumed that training in communication is 'hidden' within the overall curriculum, in that it is indirectly dealt with in the discussion of various topics, and at worst, there has been the belief that intelligent people (such as pharmacy undergraduates) do not need training in communication (Morrow and Hargie, 1985).

However, during the past 20 years several major reports have endorsed the need for better communication within pharmacy. In the U.S.A., the Dichter Institute for Motivational Research (1973) reported that many of the problems experienced by pharmacists could be related directly to their failure to communicate adequately the value of their service to patients. According to this report the pharmacist was stereotyped as the hidden practitioner closeted in the dispensary, typing labels and putting pills into little bottles but who did not see, speak with or touch the patient. Furthermore, the report indicated that patients expressed the desire that pharmacists should communicate more with them. Two years later, the Millis Commission (1975) also emphasised the need for good communicative ability among pharmacy practitioners, calling for an increase in communication skills training (CST) for pharmacy students.

The Association of Colleges of Pharmacy Study Committee, in their report on the preparation of students for the realities of contemporary pharmacy practice noted the issue of deficiencies in communication training and abilities and recommended that: "...core and elective courses throughout the curriculum should include instruction, guided experience, and formal evaluation and feedback to students regarding their written and oral communication" (Chalmers, 1983). A survey by the Association in 1979 indicated that out of 61 schools responding 48 were offering formal classroom instruction in communication skills (Pillow and Schegel, 1981). Indeed, Lezberg and Fedo (1980) have indicated that in the U.S.A. communication skills training is usually an integral part of the pharmacy undergraduate curriculum. Millis (1976) summarised the link between the behavioural sciences and pharmaceutical education in the U.S.A. as follows: "We believe that pharmacy is concerned with drugs and the people who consume them. Complex as drugs are, people are even more complex - chemically, biologically, emotionally, intellectually and socially. In our judgement, behavioral science is as much a 'basic' science as chemistry."

The situation in the U.K. significantly lags behind the U.S.A. with respect to this aspect of training. Only recently has there been a direct focus on communication as being of fundamental importance to the practice of pharmacy. The Working Party report on pharmaceutical education and training (Pharmaceutical Society of Great Britain, 1984) stressed the importance of developing the interpersonal skills of students and graduates, 
pointing out that without such skills pharmacists would not have received an adequate preparation for practice. This report asserted that: "in the preparation for a vocational career, academic staff and pre-registration tutors have a joint responsibility towards the development of interpersonal skills of their students and graduates, respectively. Without these, pharmacists will not have the basis for the provision of the full range of professional services which should be available in community practice". Indeed, a satisfactory level of communication skills was suggested as a criterion for graduation and professional registration by report of this Working Party, which stated: "...it will be even more important in the future for students to be able to communicate satisfactorily with the public and with members of other health professions. Otherwise they should not expect to graduate and register."

This has been supported in the report of the Nuffield Committee of Inquiry into Pharmacy (1986) which stressed the importance of communication to effective practice and clearly identified "pharmacy's neglect of its own social context, and social science's neglect of pharmacy". The report advocated that the pharmacy curriculum should be restructured to include the teaching of behavioural sciences especially in relation to the behaviour of healthcare professionals and patients. Specific attention was also drawn to the importance and need to develop communication skills training as part of both undergraduate and postgraduate education. The Committee recommended the testing of oral skills at the end of the preregistration period, which students would have to successfully complete before registration. Furthermore, the Inquiry Committee recommended that "research into pharmacy practice in cooperation with social and behavioural scientists should be increased".

The importance of these issues was reinforced in the same year by the Government's discussion paper on Primary Health Care (Department of Health and Social Security, 1986) which highlighted the need for pharmacists' training to supplement their scientific training with skills relevant to their wider roles, that is, skills in communication, counselling and behavioural science. Against this background, the Department of Health (London) in conjunction with The Royal Pharmaceutical Society of Great Britain mounted a national initiative into the development of a CST package to meet the recognised needs of pharmacy trainers (Morrow and Hargie, 1988).

There are therefore a number of reasons as to why pharmacists need to pay more attention to their relationships with patients. In addition to those already mentioned, another factor may be financial, in that research in the U.S.A. has shown that many patients use mail order services to obtain their medications, owing to dissatisfaction with pharmacist communication (Enriquez, 1986; Dickinson, 1987). This underlines the need for pharmacists to be more than 
dispensers of medicines, since as Leufkins (1986) has pointed out: "pharmacists who have the will and opportunity to expand their patient oriented services can expect an improvement in their image as health professionals." It has also been shown that compliance with prescribed medical regimens improves when pharmacists adopt a more active role in the practice setting (Berger and Felkley, 1989). A final reason for greater involvement with patients is that some pharmacists have faced legal action due to a failure to counsel patients on prescription drug therapy and indeed at least ten U.S.A. States have introduced mandatory patient counselling requirements (Simonsmeier, 1989). In the past, the doctor was seen as prescriber and the pharmacist as dispenser of medications. However, recent changes in standards of practice and expectations concerning the pharmacist's role as counsellor may carry with them professional legal responsibilities.

\section{Communication Skills Training In Pharmacy Education}

Historically, therefore, the discipline of communication has been a neglected part of pharmacy training. Teaching in this area can be traced to the early 1970's in the U.S.A. where the majority of pharmacy schools offer formal classroom instruction in communication skills (Pillow and Schegel, 1981). Smith (1980) proposed that every graduating student should be familiar with the various communication techniques pertinent to practice, identifying four essential areas of skill that graduate students should attain. These are the ability to communicate effectively at the patient's level of understanding, to recognise and use basic interviewing techniques in the course of medication history taking and drug consultations, the ability to communicate with other health professionals and finally, to recognise and interpret nonverbal communication. Yet, ongoing scrutiny of course content and the strategies used to develop professional social skills (Anderson et al., 1977; Benrimoj et al., 1981; Gardner et al., 1983; Jones, 1984; Gardner and McGhan, 1986; Morrow, 1986) has consistently revealed considerable variation in the teaching undertaken .

An analysis of the U.K. experience of communication skills training highlighted its limited application. In their survey of eighteen schools of pharmacy in the U.K. and Ireland, Hargie and Morrow (1986a) found that three pharmacy schools indicated that they did not include a communication component within the undergraduate curriculum. Of the remaining fifteen schools, only four indicated that they devoted twenty hours or more per student to such training. In five schools less than seven hours per student was allocated to CST; four schools stated that the amount of time given varied; and of the remaining two, one devoted ten hours and the other thirteen hours. Schools differed in relation to the nature of training methods 
used. Twelve made use of roleplay, four of closed-circuit television and six used exemplar video films, with only four institutions using all three of these teaching methods.

Thus, it may be appreciated that in view of the variation in the teaching provision of communication skills training at the undergraduate level, although individual pharmacists and professional organisations may call for greater communication with patients, there would appear to be a lack of consensus among the teaching institutions as to the importance of CST for ensuring graduate competence to practise.

Although some programmes have been described in the literature, there is little evidence within pharmacy to indicate that CST is widely conducted at the postgraduate level as part of a continuing education programme (Dickson et al., 1989). In the U.S.A., individual programmes to develop the social skills of practising pharmacists have been described (Love et al., 1978; Hanson, 1981), and within the U.K. a major initiative in which the disciplines of pharmacy and communication have been brought together to mount successful endeavours in the interpersonal dimensions of pharmacy practice has been detailed (Morrow and Hargie, $1985 ; 1987 \mathrm{a})$. Given the ever-changing role of community pharmacists as they respond to the needs of the community which they serve, the necessity for the extension of CST programmes to meet identified ongoing demands of practice can be appreciated and indeed is increasingly accepted by pharmacy trainers. Some of these demands are outlined in the following section.

\section{Identifying Communication Skills in Community Pharmacy Practice}

An overview of the literature pertaining to the communication issues facing health professionals in general and pharmacists in particular has emphasised the need for continued empirical research to ascertain the nature of individual skills necessary for effective pharmacist-patient interaction within the context of community pharmacy. As Du Vall and Lash (1984) put it: "As we dispense these potent medications we should be able to offer more than a prescription vial. We should try to give more of ourselves". There is, however, a need to identify exactly which dimensions of interpersonal communication are most pertinent for community pharmacists and in what contexts of practice.

It is therefore now widely accepted that the quality of practitioner-patient communication is fundamental to effective health care (Ley, 1988). The question then arises as to exactly what constitutes successful interpersonal communication? What distinguishes good performance from poor performance? How can skilled performance be recognised and analysed so that 
training programmes can be instituted to develop interpersonal competence? What are the elements of the interpersonal process which when integrated form a co-ordinated whole, and result in the goals of each party being achieved? What are the interpersonal skills required by pharmacists and what are the main skill deficits within this profession? Are there specific situations in pharmacy practice which require specialised interpersonal skills? These are some of the questions which this project set out to answer.

The main aim of the research was to identify effective and ineffective communicative performance by community pharmacists, and thereby to validate and delineate the content of CST programmes for pharmacists. Against this background it is clear that communication and patient satisfaction must form important elements of any quality assurance programme in pharmacy practice. Yet, more needs to be done in order to determine what the actual standards of practice should be, as distinct from the activities to be engaged in, or indeed, how practice should move to meet the desired standards.

One system which has been of growing interest in the analysis and identification of core communication issues across a range of professional contexts is the Communication Audit. This is a method which produces "a comprehensive and thorough study of communication philosophy, concepts, structure, flow and practice" (Emmanuel, 1985). The best known audit system is that developed by Goldhaber and Rogers (1979) for the International Communication Association. They itemise a number of objectives of the audit system, which illustrate how it allows us to: describe individual, group and organisational patterns of actual communication behaviours; determine the amount of information underload or overload associated with the major topics, sources and channels of communication; evaluate the quality of information communicated from and/or to these sources and the quality of information relationships; identify the operational communication networks and determine potential bottlenecks and gatekeepers of information; identify categories of recurring positive and negative communication episodes; and identify how and in what ways communication processes and procedures can be improved.

Communication audits have proved to be extremely beneficial in charting the actual patterns of communication which occur in any particular context and also in allowing all of the participants to express their views concerning how these could best be improved (Downs, 1988). It is therefore a method of gaining information in order "to solve communication problems, to keep the communication system operating, to improve communication, and to create more efficient and effective ways of communicating" (Goldhaber and Rogers, 1979). This information can be gathered in a variety of ways. For example, questionnaires can be administered to all participants asking them to evaluate current communication practices and 
to identify areas of strengths and weaknesses and suggest how improvements could be effected. Similar information can, of course, be obtained from interviews with participants. Other methods for collecting information include actual observation, recording and analysis of interpersonal encounters; diary analysis to ascertain whom individuals have interacted with and how often over a given period of time; and self-recording of interactions by participants on paper following each interactive episode. The present investigation was focused upon one dimension of the communication audit, namely the actual behaviour of community pharmacists in their interactions with patients and the method employed was therefore that of video-recording pharmacist-patient consultations.

Three main styles of approach have been proposed for the purpose of skill identification during interpersonal communication, namely the analytical, the intuitive and the empirical and these can be employed to identify the core skills central to effective practice in any professional context (Ellis and Whittington, 1981). The analytical method is, in essence, an armchair theoretical approach to social skill identification where "skills emerge from theory and analysis" (Ellis and Whittington, 1981). It requires no observation or measurement, but is the result of deductive processes based upon delineating the hypothesised purposes of interactive episodes in particular situations and deducing from these the skilled actions deemed essential for effective performance. Thus, it may be considered that some of the objectives in pharmacy practice are to diagnose patient problems, provide information on medication, and encourage compliance with therapy. Following on from this it could then be postulated that the skill concepts of questioning, explaining and influencing will be important elements for the pharmacist to master.

By contrast, the intuitive approach relies upon the intuitions of experienced practitioners to produce a list of appropriate skills for effective performance. It is experiential in nature and relies upon a reflective style of analysis, whereby the experienced professional is encouraged to make comments such as 'When I was in that situation I found it was useful to....' It is, therefore, inductive in that as experiences are collated, shared and discussed with other professionals, it is possible to build up a picture of what are generic key skills, and also which situations demand special skills.

The empirical approach is distinct form the former two, as it involves "systematic observation, recording, categorisation and analysis of interpersonal interaction to identify skills and groupings of skills" (Ellis and Whittington, 1981). In other words, this represents the application of the traditional scientific method to the study of interpersonal encounters through the use of behaviour analysis of professional encounters. Within this approach there are two main methodologies which can be employed, namely task analysis and constitutive 
ethnography (Dickson et al., 1989). The former involves shadowing someone as they work and noting what tasks they perform. It suffers from the major disadvantage that, while it identifies the functional elements of professional practice, it does not give any indication of the level of skill with which the practitioner performs them; nor does it provide information concerning what constitutes effective practice.

Constitutive ethnography, on the other hand, facilitates the identification and analysis of effective interpersonal communication. This approach, which is part of what is referred to as the 'consultative' research paradigm (Caves, 1988), involves capturing a range of interactive events on video and subsequently subjecting these to intensive peer analysis and evaluation. Thus, the ethnographer is concerned to document at a more micro level the interactional behaviour of participants. It is therefore possible to delineate in detail all of the behaviours deemed essential for effective communication. It is also possible to begin to identify useful strategies for patient consultations which make the interaction more effective and more satisfying for the participants. Moreover, the importance of the nonverbal elements of behaviour can be identified and specific cues which moderate, control and facilitate interactions can be elicited, thereby giving direction to those elements of skilled performance which need to be developed or trained. Overall then, constitutive ethnography "..is directed to analysing and identifying aspects of interpersonal behaviour which occur in social interactions in order to chart those skills and strategies which go to producing skilled performance" (Dickson et al., 1989).

The objective of the present research investigation was to employ the constitutive ethnographic approach to the community pharmacy practice situation. As mentioned earlier, few empirical analyses have been reported of the actual pharmacist-patient interface, in terms of the process of communication. Rather, other methods have tended to be employed to investigate the effectiveness of community pharmacists. Various surveys have been conducted to determine consumer attitudes to, and experiences of, pharmacy services (e.g. Hargie et al., 1992; Williamson et al., 1992), there have been a number of pharmacist selfreports of performance (e.g. Laurier et al., 1989; Povey et al., 1990) and the 'agent provocateur' approach has been employed to test pharmacist reactions to patients presenting with a range of problems (e.g. Consumers' Association, 1991).

The investigation by Morrow and Hargie (1987b) of critical incidents in the context of pharmacy practice represented an initial attempt to ascertain the pertinent issues of interpersonal communication as perceived by practising pharmacists. Their data, derived from worksheets completed by a group of 30 pharmacists working in hospital, community and administrative practice, indicated that pharmacists felt that communication could be 
hampered because of difficulties experienced in the course of interacting with problem patients/patients. The difficulties identified included reference to paediatric patients and to patients with problems of addiction, depression and disability. Participants went on to identify types of communication difficulties that were presented by problem patients. These were classified in terms of nonverbal communication, difficulties associated with the gathering and giving of information, evaluative difficulties (e.g. the assessment of patient needs and understanding) and miscellaneous difficulties which included the resolution of ethical, legal and financial conflicts, time constraints in pharmacist-patient interactions and ensuring patient satisfaction.

Having identified 'problem' patients and the difficulties of dealing with these groups, Morrow and Hargie (1987b) explored the kinds of situational difficulties facing pharmacists. These were found to include having to deal with patients' embarrassing problems, psychological/emotional problems, problems arising from disability, dealing with terminal illness and having to deal with financial problems. Finally, pharmacists' identification of other factors which influenced their interactions with patients, included reference to the pharmacist's personal characteristics, features of the pharmacy environment and other considerations such as the geographical location of the pharmacy and the availability of time to communicate with patients. In the light of these findings, it may be appreciated that, given the myriad of variables presented as potentially impinging upon communication in pharmacy consultations, the need to provide communication skills training for pharmacists and ensure communication competence among these health professionals is vital.

In relation to the informational role of the pharmacist, Berardo et al. (1989) identified four main categories of information provided in the course of patient consultation. These were concerned with information about how to take the medication, side effects, dosage and number of doses per day. In addition, they report that the workload of the pharmacy did not affect the number of dispensing episodes that included consultations with patients. However, as these findings solely related to the imparting of information and did not indicate the nature of the specific communication skills used by participating pharmacists in the course of such interactions, the need to give specific consideration to the key communication skills utilized in the context of community pharmacy remains crucial.

Wilson et al. (1989) also carried out empirical research in community pharmacies, in which they employed a combination of audiorecording, direct observation and interviews to evaluate patient understanding and recall of instructions and advice given. However, the primary focus of this research was upon product information rather than the process of communication per se. In another such investigation, audiorecordings were made of over 700 
pharmacist-patient interactions in community pharmacies in the London area and it was found that the average duration of consultations was 1.6 minutes, with pharmacists asking a mean number of 3 questions, and giving an average of 4.4 items of information or advice, per consultation (Smith et al., 1990; Smith, 1992). Furthermore, Fisher et al. (1991) have shown that the amount of time pharmacists spend speaking to patients about medicines is on average 3.5 minutes per hour.

It is clear that most of the studies in the pharmacy context have tended to focus on the product (clinical/drug information) aspect of practice with resulting dearth of research into the process of pharmacist-patient communication. In contrast, there has been more processoriented research in other health professional areas. For example, it is some 17 years since a detailed study was conducted of doctor-patient interaction (Byrne and Long, 1976). Likewise, similar studies have been carried out in nursing (Faulkner, 1984) and speech therapy (Saunders and Caves, 1986).

There was therefore a clear need within the pharmacy profession for an investigation of effective interpersonal skills. The benefits of such research were anticipated as being of major significance, both to the competence levels of pharmacists and the satisfaction and compliance of patients. The stated aims at the outset of the project were as follows.

1. To identify what constitutes effective, as opposed to ineffective, communication practice in pharmacy.

2. To identify and categorise the range of specific social skill elements that constitute effective performance in pharmacy practice.

3. To determine the communication issues associated with particular patients.

4. To determine the communication issues associated with specific health problems.

5. To provide, through the empirical identification of effective social skills, an appropriate and validated content for communication skills training (CST) courses in pharmacy. 


\section{Chapter 2: Methods and Procedures}

\section{Introduction}

The consultative design of this research investigation followed that of Saunders and Caves (1986) who employed constitutive ethnography to identify the core interpersonal skills of speech therapists. Constitutive ethnography for skill identification involves the use of an approach in which experienced professionals view a range of videorecorded episodes of actual interactions involving themselves and their patients (See Chapter 1). They then analyse these in depth both individually and in groups in order to identify and describe in detail what they, as experienced or 'expert' professionals, regard as the constituents of effective and ineffective performance. In other words, it is behaviour analysis by those involved in the communication episodes and so is ethnographic in design.

This study also adopted the constitutive ethnographic pattern of building from individual opinion and analysis through to group sharing and pooling of knowledge. In summary, the research procedure was that once pharmacists had been recruited for the study, videorecordings were obtained of a range of their consultations with patients in the pharmacy; secondly, these were then analysed individually by the pharmacist concerned; thirdly, groups of three pharmacists met to share their expertise and evaluations and also to scrutinise the consultations of each other; and finally, the entire study group of pharmacists met to agree the ultimate list of identified and delineated effective community pharmacy interpersonal skills. One other form of expertise was also employed, in that two of the project team who were behavioural scientists used their expertise to categorise behaviours identified by the pharmacists into relevant skill groupings.

\section{Recruitment of Pharmacists}

From the inception of this research project it was accepted that one of the most difficult problems would be the recruitment of the target number of 15 pharmacists from different community pharmacies (representing $3 \%$ of all community pharmacies in Northern Ireland; and $6 \%$ of all community pharmacies in the Greater Belfast area) to participate in the study. Since participation would necessitate allowing the research team to videorecord all of their interactions over a set period and would then require a substantial time commitment to the ensuing analyses of these recordings - often in the evenings - it was clear that it would not be 
possible to randomly select a set number of pharmacists and request that they participate! As the aims of the project were to identify what constituted effective communication within community pharmacy practice while concurrently highlighting those aspects of pharmacistpatient communication deemed to be ineffective, the authors were also aware of the potential feelings of vulnerability of those who might be interested in participating in the study. Therefore, the need for considerable tact was recognised at the outset, not only to generate sufficient interest in the project and to recruit study participants, but also to ensure the continued support and commitment of participating pharmacists beyond the period of data collection into the time-consuming stage of video analysis.

As a means of recruitment, an information leaflet was drawn up (Appendix 1). In response to the findings of Saunders and Caves (1986) who in a similar study reported the need to allay any suspicion among speech therapists that their communication skills were being assessed by 'outsiders', the recruitment leaflet emphasised that community pharmacists were considered as experts in their own field and their contribution to pharmacy practice innovation was therefore essential. This leaflet was posted to all pharmacies in Greater Belfast as listed in the 1990 Pharmacy Register (Pharmaceutical Society of Northern Ireland, 1990).

The decision to confine the initial mail shot to this area was taken in view of the practicalities of data collection and analysis. While it would have been interesting to ascertain whether there were differences in the issues of pharmacist-patient communication between urban and rural communities, in order to complete the project within the time schedule participants had to be readily accessible. This was necessary both to facilitate the considerable number of videorecordings which had to be made and to reduce the travel time for those pharmacists who would be participating in the subsequent analyses of these recordings at both universities in the Belfast area. As a result the catchment area for the study had to be that of Greater Belfast. Two hundred and fifty leaflets were posted to all pharmacies in this area. Concurrently, publicity was generated about the project by means of a press release which appeared in all of the relevant daily and weekly newspapers, while two members of the team talked about the project at peak time ( 8.30 a.m.) on a B.B.C. N.I. radio programme.

A total of $28(11.2 \%)$ pharmacists returned the attached reply slip, providing a telephone number at which they could be contacted to receive further information about the project. Upon receipt of reply slips the project officer contacted the pharmacist by telephone to explain the research rationale and what would be required of study participants. At this stage interested pharmacists were encouraged to ask questions and voice any opinions about the 
study and at the end of the conversation the project officer arranged to visit the pharmacy at the pharmacist's convenience to discuss the project in greater detail.

Following this initial telephone contact the project officer visited each pharmacy to discuss the project with the pharmacist and to answer any questions that they, or other staff members, had. In view of the use of the constitutive ethnography technique for analysing the data, the necessary commitment to the project was tactfully emphasised. It was also explained that while no payments would be made to those participating in the research, locum fees would be paid when appropriate and all travel expenses incurred would be reinbursed. At the same time, assurance was offered that the project team was fully appreciative of the professional demands of the study group. It was important to emphasise that the pharmacy would not be disrupted by the presence of the project officer and one technician during the recording sessions, and that ultimate control of the recording situation remained with the pharmacist at all times. The fact that the pharmacists would be given a high degree of 'ownership' of decisions made throughout the project was underlined. This visit also enabled the identification of possible problems regarding the logistics of the videorecording set-up (space for camera angles, siting of the camera etc.) which were subsequently discussed with the technical staff. At the conclusion of these detailed discussions, fifteen community pharmacists agreed to participate in the study.

\section{The Study Participants}

The 15 pharmacists who participated in the study comprised 6 females (40\%) and 9 males $(60 \%)$. Eight members of the group (53\%) owned the pharmacy in which they worked, while the remaining 7 (47\%) managed, or were joint manager, of the pharmacy. The age of study participants ranged between 24 and 59 years (mean $=37$ years), and the length of qualification ranged between 1 and 38 years (mean $=12$ years). Six of the study participants $(40 \%)$ had received some communication skills training as part of their undergraduate degree course. This had consisted of videotaped roleplay of a selection of pharmacist-patient scenarios coupled with feedback and discussion. Each pharmacist had attended continuing education courses since graduation. The greater proportion of courses attended were pharmaceutical in nature, offering instruction about disease management. However, seven members of the study group (47\%) had also attended post-graduate CST courses. The 15 pharmacies were representative of community pharmacy practice. Some were situated in districts where there was high unemployment, some in the business/university areas and others in residential areas which served established families.

\section{Pilot Recording Sessions}


Pilot recording sessions were organised in each participating pharmacy. By arrangement, the project officer and technician visited the pharmacy during a quiet period to discuss the recording situation. Following observation, the technician offered advice as to the positioning of camera and sound equipment so that the communication between the pharmacist and patient could be successfully recorded without intruding upon their interaction. The recording equipment was then set up and pilot recordings made. If circumstances within the pharmacy permitted, the recorded material was played back through a TV monitor and any adjustments to the recording set-up made and re-tested immediately. Alternatively, pilot videos were later viewed by the research team and the necessary changes to the recording set-up were discussed and noted for each particular pharmacy.

\section{Patient Consent}

Following discussions with the pharmacists a system was agreed with regard to informing patients that their interactions would be filmed. Obviously it would not have been physically possible to stop each patient individually and inform them about the nature, purpose and logistics of the exercise. It was therefore decided to adopt a 'blanket' approach to informing the public about the videorecordings by producing posters that would be displayed in the pharmacy for one full week prior to each recording. These posters explained the project rationale, assured the public that all recordings would only be seen by study participants and that all tapes would be erased at the end of the study. Posters were appropriately 'updated' on the days of recording, thereby leaving patients in no doubt as to the purpose of the video taping, and to the fact that recordings were currently taking place. These posters were prominently displayed on windows, doors and around all dispensing areas in each pharmacy. This approach has been used in previous research where audiotaped recordings were made in community pharmacies (Wilson et al., 1989; Smith et al., 1990). No attempt was made to conceal the camera so that again patients would be aware visually that they were being recorded.

\section{Videotaping of Pharmacist-Patient Interactions}

In all pharmacies the camera (Panasonic portable camera WVP F10 with 8mm lens) was located in a similar position, side-on to the counter with a wide camera angle so that both pharmacist and patient could be viewed. The camera was then linked to the videorecorder (Panasonic VHS NV180) which was placed below the counter. The camera remained 
switched on for the entire period of filming with the videorecorder taping all events in the pharmacy. While two cameras would have enabled full shots of both parties to be obtained, given the necessity for minimalising disruption to the normal operation of the pharmacies it was not possible to have more than one camera in operation. Likewise the camera used was capable of operating in low light conditions and so no additional artificial lighting was required. A radio microphone (EDC) was placed on the pharmacist who thereby had control over its operation and could switch it off if deemed necessary in any consultation. This microphone clearly picked up the voices of both pharmacist and patient.

Each pharmacist was videotaped for between 2 and 6 hours (depending upon volume of patient throughput) in the course of a normal working day. It was decided that each pharmacist would be recorded over 3 sessions. The decision to record on 3 occasions was four-fold.

1. To provide the opportunity for any problems presented by the pharmacy situation to be resolved by the technical staff in the course of, or following, the first recording session.

2. To enable the recording of time-specific interactions within the pharmacy that were considered by the pharmacists to have an influence upon their communication with patients. In this way the pressures arising from the end of GP surgeries, work and school hours, holidays and late night shopping, could be accounted for in the course of recording sessions.

3. To reduce the likelihood that participants would 'play to the camera' by providing adequate opportunity for the pharmacists, and their staff, to become accustomed to the recording setup.

4. The recording sessions were the first occasion on which the majority of participants had been videotaped. It also represented the first occasion during which they had to anticipate viewing and analysing their own performance. Appreciating their anxiety in response to this new situation, it was recognised that multiple recording sessions help to reduce anxiety during videorecordings (Hargie and Morrow, 1986b). In this way it was felt that by session II or III the pharmacists would have relaxed in the increased familiarity of the video set-up.

Dates and times of recording sessions were negotiated between the pharmacist and project officer and a schedule organised for the completion of all recordings. Participating pharmacists were recorded for total real-time durations of between 6 and 9 hours (as mentioned earlier, the times varied according to the volume of patients being dealt with in that a smaller number of patients per hour required a longer recording period in order to reach a minimum quota of 20 consultations for each pharmacist) resulting in an overall total of 105 hours of videorecording. The greater part of material was recorded during week days when attempts were made to accommodate the pattern of activity that was typical for the 
particular pharmacy. For example, recordings were made in one pharmacy near the university during the students' half day. On another occasion, a pharmacist working in a chain store in a busy shopping mall was recorded during day time and also during the often hectic late night opening period. Another pharmacy which served an area of high unemployment in the inner city was recorded during Saturday when the 'accessibility' of the pharmacist rather than the GP sometimes left the pharmacist in the situation of having to deal with irate patients who, unable to afford OTC medications, tried to pressurise the pharmacist into providing prescription medicines with the promise of returning with a script when the surgeries would re-open.

\section{Video Editing}

The recording sessions generated 350 videotaped pharmacist-patient consultations. Upon completion of the recording phase all videotapes were logged using editing facilities which counted real time. The logging procedure served several purposes.

1. It allowed for the assessment of the nature of the dispensing practice of each pharmacist, as to whether they were more involved in the dispensing of prescribed medication, OTC remedies or providing health advice.

2. It enabled accurate calculation to be made of the average length of time spent interacting with patients.

3. It facilitated consideration of the optimum amount of time necessary for dealing with patients' problems, both in general and in specific situations.

4. It meant that specific episodes could be coded, filed and rapidly located in the course of ensuing tape analyses.

Episodes of pharmacist-patient communication were edited from the master tapes. Edited episodes had to fulfil the following criteria for inclusion in the analysis.

(i) The pharmacist had to be engaged in the dispensing of prescribed medication, OTC preparations or advising on health related issues.

(ii) The sound quality of the interaction was to be of a standard to enable ready analysis by the study group. 
(iii) The videotaped interaction had to include at least a side profile of both the pharmacist and the patient, thereby enabling consideration of the appropriateness of their nonverbal communication.

\section{Videotape Analysis}

Upon completion of the videorecording the entire group of study participants met. This was the first occasion that individuals who had agreed to take part in the study came together as a group and met with the entire project team so the social function of the evening gathering was important. A meal was provided and no analysis of tapes was programmed. Since many of the pharmacists already knew one another either from their time at university or from inservice training courses, the expectation that the evening would enhance the cohesion of the group was readily realised. This meeting also provided the opportunity for logistical matters to be finalised in terms of ascertaining dates and times when participants would be available to analyse their own tapes and those of others during the forthcoming months. All participating pharmacists agreed to attend either the Department of Communication at U.U.J. or the School of Pharmacy at Q.U.B. to analyse the tapes and reaffirmed their determination to see the project through to the end.

\section{Stage I: Individual Viewing Sessions}

During this first stage of the analysis pharmacists were asked to view the entire edited tape of their own interaction with patients and to judge whether each consultation was effective or ineffective (Appendix 2a). At this stage the research objective was to generate as many ideas as possible about what was deemed to constitute effective and ineffective communication within community pharmacy practice. Therefore, pharmacists were encouraged to write down all ideas as they came to mind. This 'individual viewing' session was negotiated between individual participants and the project officer and scheduled for an evening or day time session. At the beginning of the session pharmacists were asked to view the tape, in private, from start to finish to allow them to familiarise themselves with their own self-image on videotape.

Pharmacists were then requested to select 5 consultations (episodes) which they considered to be instances of effective communication and 5 which were considered to be ineffective. They were asked to provide written assessment of their performance by completing an individual viewing sheet for each of their 10 selected consultation episodes. This required that they described the situation in the pharmacy and indicated whether, in their opinion, the 
episode was an example of effective or ineffective communication and justifying their judgement of communication in the particular instance. To take account of any unusual situation, participants were asked to indicate the frequency with which they would typically have to deal with each of the situations included in their 10 chosen episodes (Appendix 2b).

In view of the community based nature of the project and the significance of the pharmacistpatient relationship in assessing the ensuing interaction, pharmacists were invited to draw to the attention of the group any information which, while not immediately obvious from the tape, was in their opinion nonetheless relevant when assessing the communication in the particular consultation. In many instances pharmacists took this opportunity to provide information about the nature of the relationship with a particular patient that had usually been established over many years. In their view, this was often crucial in assessing the appropriateness of dimensions such as humour or physical contact between the pharmacist and patient. Finally, pharmacists were asked to make suggestions as to how they would improve upon the communication in each of their selected episodes.

At the end of Stage I, the selected episodes were re-edited onto another videotape in preparation for the second stage of the analysis. At this point the need to attend to the anonymity of patients in consultation about particularly sensitive issues was addressed. It had been agreed that in cases where the pharmacist was involved in dealing with a highly personal problem the names and addresses of patients would be 'bleeped' out if mentioned and faces would be electronically 'mosaiced'. In practice, this was only required in one consultation episode in which a female patient presented a sample for pregnancy testing.

\section{Stage II: The Triad Sessions}

In view of the overwhelming amount of material generated during the recording sessions the second stage of the analysis involved the reduction of this material by the pharmacists. During Stage II of the analysis, pharmacists met in triads to discuss the issues of communication raised by their own 10 consultation episodes and those identified by the other two in the group. Participants were assigned to one of five triads on the basis of their availability to meet with two other participating pharmacists at set times. As a triad they were required to select one episode of effective and one of ineffective communication for each triad member from the 10 available consultations (Appendix 3).

As the initial analysis of Stage I data indicated that the study group was identifying the majority of situations from the pharmacist's perspective and with reference to dispensing or health issues raised by a particular consultation, it was necessary to focus the pharmacist's 
attention on the communication issues of each episode. Therefore, the triads were asked to re-assess the effectiveness and ineffectiveness of each of their total of 30 Stage I episodes and to analyse each episode from both the pharmacist's and patient's point of view.

Having viewed the 30 episodes, and chosen the 'best' and 'worst' for each triad member, the pharmacists were asked to complete a 'selected episode sheet' for each of the 6 episodes (Appendix 3). Pharmacists were asked to clearly identify 7 different actions of the pharmacist which were, in their opinion, instances of good pharmacist-patient communication. In addition, they were instructed to identify 5 different actions that if the pharmacist were given the opportunity to deal with the situation again they might have done differently. In accordance with Saunders and Caves' (1986) methodology, pharmacists were encouraged to approach this part of the analysis by imagining that they had a pre-registration pharmacist beside them. Therefore, as a triad, they were asked to point out to an inexperienced pharmacist instances of effective or ineffective communication. Pharmacists were also asked to describe what was taking place in the consultation in such a way that their descriptions of actions would be meaningful to someone who had not seen the videotape.

Analysis of the episodes selected by the triad was more highly structured than the Stage I analysis. Each triad was given an analysis sheet corresponding to each of the 6 selected episodes. This comprised 3 columns that were to be completed by each triad. In column I the group was asked to list the pharmacist's actions throughout the episode and in column II to describe the meaning of each action (Appendix 3). They were asked to assess the effectiveness or ineffectiveness of each listed action from both the pharmacist's and patient's perspective. Each consultation selected during the individual viewing session was assessed using the described criteria. In an attempt to overcome any problems arising from the potential dominance of individual group members, triads were instructed to appoint a secretary and co-ordinator for each pharmacist.

These triad sessions generated considerable discussion between group members in their endeavours to reach consensus and so this stage of analysis had to be divided over two sessions. In some cases, the content of selected episodes was such that the triad became 'bogged down' in the course of the analysis. At such points the project officer agreed to join the triad, assuming the role of timekeeper/referee, to ensure that the group successfully completed their task by the end of their second meeting.

Stage III: Categorisation of Communication Behaviours 
Upon completion of the triad sessions a large volume of behaviours had been generated. It was also clear that quite often the same behaviour was being described in different terms by each triad. The task remaining was that of classifying similar instances of behaviour into categories and labelling such categories. While it was originally intended that during this stage of the analysis the pharmacists should meet as a group of 15 to sort each identified behaviour into communication categories, the time and effort already invested in the labelling of behaviours in the course of the triad sessions highlighted the need for some preliminary sorting by the research team. Each behaviour identified by the triads was therefore transcribed to a computer file and categorised as belonging to one or more categories and/or sub-categories. In order to comply with the original ethos of the project which acknowledged the expertise of the pharmacists in identifying instances of effective communication within their professional practice, the researchers categorised each behaviour by adhering strictly to the original description of the action provided by the triad. On this basis behaviours were sorted into 11 broad categories and their related sub-categories.

The entire project group then met to agree the final categorisation and classification of behaviours. Each pharmacist received a copy of the effective behaviours which had been identified by the triads. They also were given a copy of the defined categories and subcategories as charted by the project team. Given the need to define each behaviour with reference to the context of the interaction within community pharmacy practice, initially the pharmacists were asked to individually re-define the categories as they saw necessary. Following consensus, any changes to the definitions of the 11 categorised communication skills were made and the modified definitions given to the pharmacists (Appendix 4).

The group was then randomly divided into 5 groups of 3 and asked to watch each of the 30 episodes in turn. Following each episode, the group was asked to individually categorise each of the already listed effective behaviours before discussing the categorisation within the group. In view of the sheer number of listed behaviours, it was necessary to adhere to a strict time schedule throughout this session. Five minutes after viewing each episode the triad was asked to categorise each of the episode-specific behaviours (Appendix 5). In instances where triads or individuals disagreed with either the categorisation or sub-categorisation, discussion ensued until consensus was reached regarding the appropriate categorisation of the behaviour (Appendix 6). Consensus also involved the need to categorise specific behaviours into more than one category. For example, the pharmacist's action of touching a distressed patient, thereby providing comfort was appropriately categorised as an instance of nonverbal communication and equally as an instance of building rapport with the patients by demonstrating sensitivity in response to their situation. 
The next stage involved pharmacists working individually, viewing each episode again and indicating on a 6 point likert scale the extent to which they considered each of the situationspecific behaviours to be essential for effective pharmacist-patient communication (Appendix 7). In cases where a behaviour was assigned to more than one category, pharmacists were instructed to complete both relevant likert scales.

In addition, pharmacists were asked to indicate on a separate scale the extent to which they felt that each of the communication skills, identified across the 30 episodes, was essential for effective pharmacist-patient communication as a general rule (Appendix 8). In this way, the relevance of particular skills to the interaction in the specific situation or similar situations (such as prescription dispensing OTC recommendation or dealing with sensitive problems) could be assessed, together with a general evaluation of the necessity for specific communication skills in the course of effective pharmacist-patient communication.

The pharmacists' ratings of the importance of each situation-specific skill along with their ratings of the skill in the general pharmacy situation were analysed using descriptive statistics. This provided information about the pharmacist's perception of the importance of each skill both in general terms, and in relation to the specific situations. As one aim of the study was to gain insight into the consensus view of participating pharmacists it was appropriate to consider the modal rating of each categorised behaviour in both the specific and general pharmacy situation. Therefore the findings as outlined in the following chapter include the modal ratings of the individual behaviours, with the actual percentage of each rating included in brackets. In the case of ties, both figures and corresponding percentage are presented. 


\section{Chapter 3: Results}

Owing to the progressive nature of the methodology, brick built upon brick, some of the results have already been referred to in the previous Chapter. However, despite some inevitable repetition, the results are presented here as a co-ordinated whole, thereby providing a full blown picture of the emergent issues and their inter-relationships. The results of the study are then discussed in detail in Chapter 4.

\section{Skills Identified}

Table 1 presents the communication categories and related sub-categories as identified and agreed by the pharmacists. In total there were 11 major categories made up from 45 more discrete elements. Tables 2 and 3 describe the nature of the interactions of the 30 analysed scenarios, 15 of which had been judged to be effective in terms of their overall communication and outcome, and 15 of which had not. The frequency of 'effective' communication skill use is also shown in Tables 2 and 3 relative to particular consultations. It should be noted that in the 15 'ineffective' consultations the pharmacists were able to identify positive examples of skill use (Table 3). However, effective communication skills were used twice as often in the judged effective episodes as in interactions where the overall performance was rated ineffective.

In terms of the overall identified frequency of effective use of specific skills, Table 4 indicates that a total of 172 instances of effective communicative behaviour were observed across the 30 analysed episodes. Building rapport, explaining and questioning were the primary skills employed, with over $50 \%$ of skills being accounted for by the first two. Persuasion was identified as an essential skill on one occasion only, while the more intimate communication of disclosing personal information was identified in two instances.

When viewed within the context of the episodes that the pharmacists judged to be either broadly effective or broadly ineffective, each of the skills was used consistently more often in the 15 'effective' episodes than in the 15 'ineffective' episodes, with one exception, that of questioning (Table 4). The difference in the use of listening and building rapport was most striking between the two groups of episodes. 


\section{Generic Ratings of Skills}

Tables 5-12 set out the pharmacist panel's assessment of the general importance of the individual skill elements in each broad category, independent of any specific context. The percentage figures quoted are for the highest proportion of votes cast for an individual rating, within a range from ' 6 ' indicating that the skill element is definitely essential for effective pharmacist-patient communication to ' 1 ' that it is definitely not essential (Appendix 8).

Pharmacists' opinions of the importance of each of the sub-elements of questioning is presented in Table 5. Here, over two thirds of the group voted the action absolutely essential for four of the five sub-elements in every case (modal 6), with a range of 4-6 for all pharmacists. However, a minority scored 'showing interest' as absolutely essential, and for the whole group the modal score ranged from 2-6.

In relation to the three sub-elements of listening (Table 6), the overwhelming majority rated the ability to show sympathy and empathy and encourage patient disclosure as essential. Eighty percent felt the demonstration of interest beyond the immediate problem to be either probably or definitely essential, although a further $20 \%$ were unsure as to its importance.

Table 7 presents the pharmacists' analysis of the elements they viewed as contributing to assertiveness skills. Only $40 \%$ viewed reference to other health professionals as definitely essential to maintaining their own rights, with a modal range 1-6 across the whole group. A similar picture was found in terms of politeness in standing firm, although the range (4-6) in this case was narrower and at the upper end of the scale.

The various dimensions of explaining skill identified by pharmacists as being important to their role are presented in Table 8. Eighty seven percent viewed 'reasoned instruction' as critical to effective communication, whereas less than half the group (40\%) believed that directing alone was definitely essential. More importance was attached to the information function of the pharmacist and the need to provide patient reassurance through explanations. Over $50 \%$ of the panel allocated the repetition of directions a modal rating of 6 , with $94 \%$ rating reinforcement/emphasis an absolute or virtually essential part of explaining.

Of the elements contributing to nonverbal communication (Table 9), eye contact was rated the most essential skill, with $60 \%$ voting it modal rating 6 . In only three other cases, proximity, positioning and smiling/nodding head, was a 6 rating given and that by a minority vote. Touch was thought to be essential by $40 \%$ of the panel, while $53 \%$ rated patient 
examination 4, indicating their uncertainty as to its degree of importance to effective communication in the pharmacy context. Illustration/demonstration/display as nonverbal means of communication were viewed with even more uncertainty $(33 \%)$.

From Table 10, it is evident that a large number of issues has been categorised into rapport building. Of most significance is the unanimous view that preserving confidentiality is a nonnegotiable part of good practice. Demonstrating concern, helpfulness, accessibility/availability, offering reassurance all scored $80 \%$ or more agreement at the modal 6 level. Similarly, politeness under all circumstances and showing interest were considered definitely essential by over $70 \%$ of the panel. Interestingly, despite the high ratings for concern and interest, human warmth, as a separately identified category, was only rated absolutely essential by $53 \%$ of the pharmacists. At the same time, there was a high degree of consistency of evaluation of reassurance as an important behaviour within the context of explaining (73\%) (Table 8$)$, and building rapport $(80 \%)$.

Table 11 shows three identified aspects of opening an interaction. These range from a general acknowledgement, to a personal greeting using the patient's name, or to a task centred greeting to identify who the individual is, the latter being considered most important and definitely essential by $67 \%$ of the panel. In contrast, initiating the closing of an interaction was not a behaviour pharmacists considered essential to effective communication, the largest vote (40\%) giving it a highest modal score of 4 (Table 12). Expressing thanks to the patient and politeness were, however, considered crucial aspects of any closing sequence.

Suggesting/advising, defined as offering a personal/professional opinion as to a particular course of action, while at the same time allowing the patient to take the final decision, was identified as a discrete category on its own. Here, there was a strong consensus as to its fundamental importance to effective communication, 73\% voting it modal rating 6 with an overall range of 4-6. Similarly, disclosing personal information, often referred to technically as self-disclosure, was categorised as a distinct entity. Forty seven percent gave it a modal rating of 5. However, the ratings ranged between 2 and 6 , some respondents considering the behaviour almost inappropriate. Finally, persuading behaviour was identified as an element in the analysed scenarios. In terms of its importance the modal scores ranged from 2 to 6 . One third of the group scored it 4 with another third rating it 6 .

\section{Context-specific Ratings of Skills}


Tables 13-23 set out the complete list of the pharmacist panel's assessment of the importance of the individual skill elements in each broad category, specific to the context in which the behaviour was used (as distinct from their general importance across all situations). The percentage figures quoted are for the highest proportion of votes cast for an individual rating, within a range from ' 6 ' indicating that the skill element is definitely essential for effective pharmacist-patient communication to ' 1 ' indicating that it is definitely not essential (Appendix 7). These tables also exemplify the nature of the behaviours displayed.

Table 13 illustrates the analysis of questioning skills, which are rated consistently highly in the definitely essential (score 6) category. It is, however, of interest that in the diagnostic test situation, the modal ratings for questioning in the identified sub-categories uniquely spanned the whole range 1-6, with the majority of other situations being 4-6. While there was a large degree of consistency between the general scores in Table 5 and those situation-specific scores in Table 13, the almost unanimous 6 general rating for questioning relative to other medication taken was not matched in the specific situation, on average only $52 \%$ voting 6 over a range $2-6$.

In the case of listening (Table 14), the pattern that emerged across the three sub-categories differed from the general picture in Table 6. Showing sympathy/empathy only scored about $75 \%$ of its generic value. Encouraging patient provision of information showed a similar profile, while showing interest beyond the problem was rated correspondingly higher in the specific context. In the situations where the emotional charge may be normally regarded as high (e.g. domestic violence and terminal illness) the listening importance level was at its highest (6-80-87\%).

Where assertive behaviour was used, $60 \%$ or over of the pharmacist panel voted its importance 6 in all cases, with the modal range 4-6 (Table 15). This contrasted with a much lower level of importance reported in Table 7.

Table 16 highlights a wide range of examples of explaining skills. Overall, reasoned instructions in specific contexts were rated 6 by $73 \%$ of the panel, compared to $87 \%$ in Table 8. The importance of directing was consistent from the general to the specific, while informing as a sub-skill had a wider modal rating range across the various contexts in which the behaviour was displayed, as distinct from its general rating 5-6 (Table 8). Out of 19 'informing' instances only four were rated 6 at a $60 \%$ level, given that this was viewed as a standard for level of importance (Table 8). Similarly, explaining for reassurance was voted at a lower level of importance when analysed in context. In contrast, repetition had an increased importance profile in those situations where it was used, while reinforcement and emphasis followed the opinions expressed in Table 8 . 
While nonverbal communication pervades all communication, it was only identified as a specific skill on 14 occasions (Table 17). A high degree of consistency was observed from Table 9, although it is of interest to note that while illustration/demonstration/display had the highest percentage voting 4 (Table 9), this rose to a mark of 6 when rated in context. Similarly, standing still was consistently rated 6 by the majority of respondents when judged in context.

The comparison of Tables 18 and 10 related to the importance of rapport building in pharmacist-patient interactions showed a number of differences from the general situation to the specific. Of the 13 sub-elements of rapport building four were voted definitely essential by a greater number of the panel when analysed in context; seven were less favourably rated with two equivocal. Preserving confidentiality was the only element across all skills which was considered definitely essential by all pharmacists, yet that unanimous support had fallen considerably when judged in the actual consultation situation.

Overall, opening was not seen as particularly important in that while opening occurs in all interactions, it was only identified 10 times in 30 episodes. On five occasions the greeting included the patient's name (Table 19) and was judged definitely essential by $60 \%$ overall, yet its best rating in general was 5 by $53 \%$ of the panel (Table 11 ).

Closing was even less frequently identified as a skill compared to opening (Table 20), although there was no significant difference from the pharmacists' views of the importance of closing per se (Table 12) and their analysis of closing in context.

Table 21 highlights the 10 examples of suggesting/advising identified by the pharmacist panel. In no case did the rating reach that of $6(73 \%)$ as set by the panel as their original rating of that behaviour.

Two examples of the pharmacist identifying with the patient by recounting a personal experience were identified (Table 22). Although they both occurred in the effective episodes, they were only considered definitely essential by $40 \%$ and $53 \%$ of the panel. This was higher than its rated general importance, yet the modal score ranged from 3-6. Persuading was only identified on one occasion (Table 23), $40 \%$ of the panel giving it a 6 rating.

\section{Prescription and Non-prescription Consultations}


Tables 24 and 25 identify the nature of the interactions, twelve of which were related to prescription dispensing and 18 to other types of consultation. Out of 11 skill areas, 7 was the largest number of discrete instances of different skills used in a single consultation, occurring on two occasions namely, terminal illness (Table 24) and domestic violence (Table 25). The highest number of total skills employed overall in any specific interaction was 14, and this occurred in two consultations - domestic violence and pregnancy testing - both of these within the non-prescription episodes (Table 25). In all of the 30 episodes, explaining was used in 24, questioning in 18 and rapport building in 17. Suggesting/advising was only used in the non-prescription dispensing situation, while explaining featured in comparatively more prescription than non-prescription consultations. 
1.

a

b

$\mathrm{c}$

d

e

2.

a

b

c

3.

a

b

4.

a

b

c

d

e

$\mathrm{f}$

5.

a

b

c

d

e

f

\section{Questioning}

Re: patient details, name, age etc.

Re: symptoms, previous action taken, cause of health problem, duration, lifestyle, previous action of other health professionals Checking out/exploring situation

Showing interest

Re: other medication being taken

\section{Listening}

Showing sympathy/empathy

Encouraging patient to provide information

Showing interest (beyond the problem)

\section{Assertiveness}

Enhancing credibility by referring to view of other health professionals Pharmacist politely standing ground

Explaining

Reasoned instructions

Directing

Informing

Explaining for reassurance

Repetition

Reinforcing/emphasising

\section{Nonverbal communication}

Tone of voice

Standing still

Eye contact

Proximity

Positioning

Smiling and/or nodding head 


$\begin{array}{ll}\mathrm{g} & \text { Using hand gestures } \\ \mathrm{h} & \text { Touch } \\ \mathrm{i} & \text { Illustration/demonstration/display } \\ \mathrm{j} & \text { Pharmacist examining patient }\end{array}$

Table 1 (cont.)

6.

Building Rapport

a

b

Showing genuine concern

c

d

Showing pleasure/happiness

Greeting by name

Being helpful

e

Accommodating patient's needs

$\mathrm{f} \quad$ Politeness in manner

g Use of humour

$\mathrm{h} \quad$ Being available/accessible

i Engaging

j Offering reassurance

k Preserving confidentiality

1 Showing warmth

$\mathrm{m} \quad$ Showing patient interest

7.

Opening

$\mathrm{a}$

Greeting, general

b Greeting by name

c Identifying patient by name (script check)

8.

\section{Closing}

a

Thanking patient

b

Initiating ending of interaction

c Polite closing

9.

Suggesting/Advising

10.

Disclosing personal information

11.

Persuading 
Table 2 Contexts of consultations and skill usage in the selected effective episodes

Nature of consultation

No. of effective skills identified

Pregnancy test

Leg ulceration 10

Angina 9

Cold symptoms 7

Terminal illness 9

Nasal congestion 8

Complaining patient 7

Antibiotic for throat infection 6

Eye drops 2

Domestic violence 14

Cough bottle (I) 5

Conjunctivitis 9

Antibiotic for dental patient. 6

$\begin{array}{ll}\text { Incorrect prescription details. } & 7\end{array}$

Request for haemorrhoid medication 6

Total 119 
Table 3 Contexts of consultations and skill usage in the selected ineffective episodes

Nature of consultation

No. of effective

skills identified

Cough bottle (II)

3

Holiday medication $\quad 4$

Request for liquid paraffin $\quad 4$

Request for specific medication 1

Food supplement 3

Request for antibiotic (I) 5

Request for throat medication $\quad 6$

Face spot 3

Antibiotic for child (I) 3

Antibiotic for child (II) 3

Antibiotic for adult (I) 3

$\begin{array}{ll}\text { Request for antibiotic (II) } & 7\end{array}$

Antibiotic for adult (II) 2

Repeat angina prescription 3

Injured dog 3

Total 53 
Table 4 Frequency of effective communication skills identified by pharmacists according to overall rated episode

Frequency of effective skill use

Effective episodes Ineffective episodes

Total

(\%)

(\%)

(\%)

\begin{tabular}{|c|c|c|c|c|}
\hline Questioning & 11 (6.4) & $13(7.6)$ & 24 & $(13.9)$ \\
\hline Listening & 11 & $1 \quad(0.6)$ & 12 & $(7.0)$ \\
\hline Assertiveness & $3(1.7)$ & $1 \quad(0.6)$ & 4 & $(2.3)$ \\
\hline Explaining & $27(15.7)$ & $17 \quad(9.9)$ & 44 & $(25.6)$ \\
\hline Nonverbal communication & $10(5.8)$ & $3(1.7)$ & 13 & $(7.5)$ \\
\hline Building rapport & $36 \quad(20.9)$ & $9(5.2)$ & 45 & $(26.2)$ \\
\hline Opening & $6 \quad(3.5)$ & $4(2.3)$ & 10 & $(5.8)$ \\
\hline Closing & $5 \quad(2.9)$ & $2(1.2)$ & 7 & $(4.1)$ \\
\hline Suggesting /Advising & $7(4.1)$ & $3(1.7)$ & 10 & $(5.8)$ \\
\hline $\begin{array}{l}\text { Disclosing personal } \\
\text { information }\end{array}$ & $2(1.2)$ & - & 2 & $(1.2)$ \\
\hline Persuading & $1(0.6)$ & - & 1 & $(0.6)$ \\
\hline Total & $119(69.2 \%)$ & $53(30.8 \%)$ & 172 & $(100 \%)$ \\
\hline
\end{tabular}


Table 5 General ratings of the importance of questioning in pharmacist-patient communication

Questioning Sub-skills

Modal

Rating

Percentage Range

6

67

4-6

name, age etc.

b Re: symptoms,

6

80

$5-6$

previous action taken, cause of health problem, duration, lifestyle, previous action of other health professionals

c Checking out/

6

$67 \quad 4-6$

exploring situation

d Showing interest

6

47

2-6

e Re: other medication

6

93

$5-6$ 
Table 6 The importance of listening in pharmacist-patient communication

Listening Sub-skills Modal

Percentage

Range

Rating

a

Showing sympathy/

empathy

b Encouraging patient

6

93

5-6

to provide information

$6 \& 5$

$40 \& 40$

4-6 the problem) 
Table 7 The importance of assertiveness in pharmacist-patient communication

Assertiveness Sub-skills

Modal

Percentage

Range

Rating

a Enhancing credibility by

4

40

$1-6$ referring to view of other

health professionals

b Pharmacist politely

6

40

4-6 
Table 8 The importance of explaining in pharmacist-patient communication

$\begin{array}{llll}\text { Explaining Sub-skills } & \text { Modal } & \text { Percentage } & \text { Rating } \\ \text { Rating } & \end{array}$

$\begin{array}{llccr}\text { a } & \text { Reasoned instructions } & 6 & 87 & 4-6 \\ \text { b } & \text { Directing } & 6 & 40 & 1-6 \\ \text { c } & \text { Informing } & 6 & 60 & 5-6 \\ \text { d } & \text { Explaining for reassurance } & 6 & 73 & 4-6 \\ \text { e } & \text { Repetition } & 6 & 53 & 4-6 \\ \text { f } & \text { Reinforcing / emphasising } & 5 \& 6 & 47 \& 47 & 4-6\end{array}$


Table 9 The importance of nonverbal skills in pharmacist-patient communication.

Nonverbal Sub-Skills

Modal

Percentage

Range

Rating

$\begin{array}{llccr}\text { a } & \text { Tone of voice } & 5 & 57 & 5-6 \\ \text { b } & \text { Standing still } & 5 & 40 & 3-6 \\ \text { c } & \text { Eye contact } & 6 & 60 & 4-6 \\ \text { d } & \text { Proximity } & 6 & 47 & 4-6 \\ \text { e } & \text { Positioning } & 6 & 47 & 4-6 \\ \text { f } & \text { Smiling and / or } & 6 & 40 & 4-6 \\ & \text { nodding head } & & 47 \& 47 & 4-6 \\ \text { g } & \text { Using hand gestures } & 4 \& 5 & 40 & 2-5 \\ \text { h } & \text { Touch } & 5 & 33 & 1-5 \\ \text { i } & \text { Illustration/demonstration/ } & 4 & 53 & 2-6\end{array}$


Table 10 The importance of building rapport in pharmacist-patient communication

\begin{tabular}{|c|c|c|c|c|}
\hline \multicolumn{2}{|c|}{$\begin{array}{l}\text { Rapport Building } \\
\text { Sub-skills }\end{array}$} & \multirow{2}{*}{$\begin{array}{c}\text { Modal } \\
\text { Rating } \\
\\
6\end{array}$} & \multirow{2}{*}{$\begin{array}{c}\text { Percentage } \\
\\
87\end{array}$} & \multirow{2}{*}{$\begin{array}{r}\text { Range } \\
\text { 4-6 }\end{array}$} \\
\hline $\mathrm{a}$ & Showing genuine concern & & & \\
\hline $\mathrm{b}$ & $\begin{array}{l}\text { Showing pleasure/ } \\
\text { happiness }\end{array}$ & 5 & 47 & $4-6$ \\
\hline $\mathrm{c}$ & Greeting by name & $5 \& 6$ & $40 \& 40$ & $3-6$ \\
\hline$d$ & Being helpful & 6 & 87 & $5-6$ \\
\hline $\mathrm{e}$ & $\begin{array}{l}\text { Accommodating } \\
\text { patient's needs }\end{array}$ & 5 & 47 & $4-6$ \\
\hline $\mathrm{f}$ & Politeness in manner & 6 & 73 & $5-6$ \\
\hline g & Use of humour & $5 \& 6$ & $40 \& 40$ & $4-6$ \\
\hline $\mathrm{h}$ & Being available/accessible & 6 & 87 & $5-6$ \\
\hline $\mathrm{i}$ & Engaging & 6 & 47 & $4-6$ \\
\hline $\mathrm{j}$ & Offering reassurance & 6 & 80 & $5-6$ \\
\hline $\mathrm{k}$ & Preserving confidentially & 6 & 100 & 6 \\
\hline 1 & Showing warmth & 6 & 53 & $5-6$ \\
\hline $\mathrm{m}$ & Showing patient interest & 6 & 73 & $5-6$ \\
\hline
\end{tabular}


Table 11 The importance of opening in pharmacist-patient communication

Opening Sub-skills

Modal

Percentage

Range

Rating

$\begin{array}{lllll}\text { a } & \text { Greeting, general } & 6 & 60 & 4-6 \\ \text { b } & \text { Greeting by name } & 5 & 53 & 2-6 \\ \text { c } \quad \begin{array}{l}\text { Identifying patient } \\ \text { by name (script check) }\end{array} & 6 & 67 & 5-6\end{array}$


Table 12 The importance of closing in pharmacist-patient communication

Closing Sub-skills

Modal

Percentage

Rating

Rating

$\begin{array}{llccc}\text { a } & \text { Thanking patient } & 5 \& 6 & 47 \& 47 & 4-6 \\ \text { b } \quad \begin{array}{l}\text { Initiating ending of } \\ \text { interaction }\end{array} & 4 & 40 & 1-6 \\ \text { c } \quad \text { Polite closing } & 6 & 60 & 4-6\end{array}$




\section{Table 13 The importance of pharmacists' situation-specific questioning behaviour}

\begin{tabular}{|c|c|c|}
\hline $\begin{array}{l}\text { Questioning } \\
\text { Sub-skill }\end{array}$ & Situation & Nature of Questions \\
\hline
\end{tabular}

a Re: patient details name, age etc. test

$$
\begin{aligned}
& \text { Pregnancy I'll just take your name and } \\
& \text { your address as well, it's } \\
& \text { just so we don't get } \\
& \text { confused. }
\end{aligned}
$$

Antibiotic for Are these for yourself? Oh

throat infection right, for your daughter?

Antibiotic for

How old is David?
Rating (\%)

5

$1-6$

6

$$
5-6
$$

Bottle (I) cough? About 3 weeks and you previous action taken, cause of health problem: duration, lifestyle,previous action of other health professionals

. haven't tried anything for it? Right, when you're coughing are able to cough any phlegm up? Yeah and have you seen the phlegm is it coloured? Right, so you'd pleurisy not so long ago? Are you taking any other medicines from the doctor? Are you a smoker?

\section{Conjunctivitis}
You have a stye coming on the upper lid? Does it feel any way crusty or sore to touch? You say the lid was stuck together when you wakened? It feels gritty?

Cough Is it for yourself? Is it a bottle (II) chesty cough? Are you a smoker at all? No, that's good.

6 4-6

Request for What sort of a cold have you 6 got? What's the worst part of it? It's in your chest? Have you taken anything for it? And you say you feel there's phlegm in your chest?

Antibiotic for Does he have a lot of problems with chest infections?

exploring Is it an early morning sample, and do you know how long your period is situation

$$
\text { overdue? }
$$

Terminal Is this osteoporosis? 
Table 13 The importance of pharmacists' situation-specific

(cont.) questioning behaviour

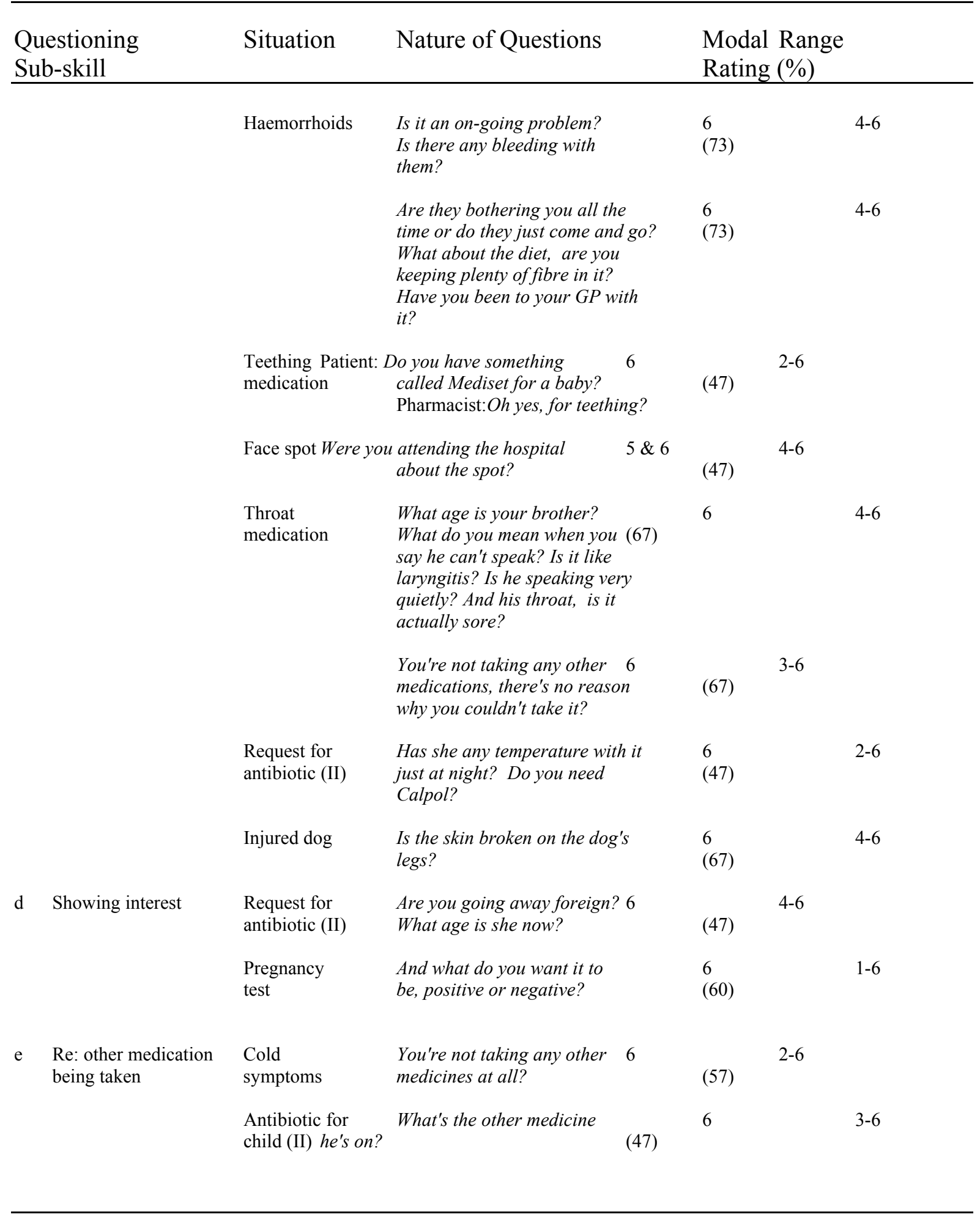


Table 14 The importance of pharmacists' situation-specific listening behaviour

\begin{tabular}{|c|c|c|c|}
\hline $\begin{array}{l}\text { Listening } \\
\text { Sub-skill }\end{array}$ & Situation & Nature of Listening & $\begin{array}{l}\text { Modal Range } \\
\text { Rating (\%) }\end{array}$ \\
\hline
\end{tabular}

a Showing sympathy/ Angina

Pharmacist by appropriate

6

$5-6$ empathy

positioning, and maintaining (73)

eye contact, conveys

attention.

Pharmacist by standing still 6

when patient is talking conveys

concern.

Pharmacist gives patient time to express feelings about their illness. violence responds to patient's need

to talk by paying full attention to what she has to say about her injuries.

Conjunctivitis Pharmacist listens to patient 6 by making good eye contact (73) and standing still.

Request for

Pharmacist gives verbal reinforcement to patient as she relates her additional health problems.

b. Encouraging patient to provide

$\begin{array}{ll}\text { Leg } & \text { Pharmacist faces patient } \\ \text { ulceration } & \text { and gives concerted eye }\end{array}$ contact; also makes appropriate 'noises' while patient talks about her leg.

Terminal Pharmacist's sympathetic indicates willingness to listen.

Antibiotic for throat infection

Pharmacist asks questions and clarifies what the customer is saying about her daughter's symptoms.

Haemorrhoids

Pharmacist actively listens, 6 responding verbally to each
piece of information that the patient gives. Food Pharmacist actively listens supplement to patient, maintaining open stance, and provides encouraging eye contact and head nods. 
Table 14 The importance of pharmacists' situation-specific listening (cont.) behaviour

\begin{tabular}{lllll}
$\begin{array}{l}\text { Listening } \\
\text { Sub-skill }\end{array}$ & Situation & Nature of Listening & $\begin{array}{l}\text { Modal Range } \\
\text { Rating (\%) }\end{array}$ \\
\hline c $\quad \begin{array}{l}\text { Showing interest } \\
\text { (beyond the problem) }\end{array}$ & $\begin{array}{l}\text { Leg } \\
\text { ulceration }\end{array}$ & $\begin{array}{l}\text { Pharmacist allows patient } \\
\text { to take her time explaining } \\
\text { the situation, paying } \\
\text { attention to her expressed } \\
\text { concerns. }\end{array}$ & $\begin{array}{l}6 \\
(67)\end{array}$ & $5-6$ \\
& $\begin{array}{l}\text { Terminal Pharmacist, realising the } \\
\text { customer's need to talk } \\
\text { about wife's illness, looks } \\
\text { up from script and gives } \\
\text { concerted eye contact. }\end{array}$ & (80) & \\
& & & \\
& & & \\
& &
\end{tabular}


Table 15 The importance of pharmacists' situation-specific assertive behaviour

$\begin{array}{lr}\text { Assertiveness Situation } & \text { Nature of Assertiveness } \\ \text { Sub-skill } & \text { Modal Range } \\ \text { Rating(\%) }\end{array}$

a Enhancing credibility Domestic

Now don't take a half Buspar 6

4-6

by referring to view

violence unless the doctor advises you (67)

you to do that. If he has you

of other health

on the Buspar it's up to him to

professionals

change the medication.

b Pharmacist politely

Complaining

Actually in a way we're both 6

standing ground

patient

right here.

5-6

We've a record that we owe you

(73)

40, they'll be in sometime this(73)

afternoon.

Request for

Well I can't give you something

antibiotic (I) until I speak to the doctor to (60)

6

find out what he would suggest.

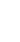

6 


\section{Table 16 The importance of pharmacists' situation-specific explaining behaviour}

\begin{tabular}{|c|c|c|c|}
\hline $\begin{array}{l}\text { Explaining } \\
\text { Sub-skill }\end{array}$ & Situation & Description & $\begin{array}{l}\text { Modal Range } \\
\text { Rating (\%) }\end{array}$ \\
\hline
\end{tabular}

\section{a Reasoned} instructions

Leg
ulceration

Don't take two to start off with, just take one a day since you have already had it (antibiotic) for two to three weeks.

\begin{tabular}{|c|c|}
\hline Nasal & Take a Karvol capsule or some \\
\hline Congestion & $\begin{array}{l}\text { Friar's balsam. Put it into some } \\
\text { boiling water and inhale it. }\end{array}$ \\
\hline $\begin{array}{l}\text { Antibiotic for } \\
\text { throat infection }\end{array}$ & $\begin{array}{l}\text { Two now, one before tea and } 6 \\
\text { one before bedtime and } \\
\text { one } 4 \text { times a day after that. }\end{array}$ \\
\hline Eye drops & $\begin{array}{l}\text { The doctor has put down } 2 \\
\text { drops to be used } 4 \text { times a day. } \\
\text { The eye can only really hold } 1 \\
\text { drop at a time so if you put } 2 \\
\text { drops in it just washes off. So } \\
\text { it would be better if she just } \\
\text { put } 1 \text { drop in and then the other, } \\
\text { and also you're better to use it for } \\
\text { a few days after the condition has } \\
\text { cleared up to make sure it's right } \\
\text { away then. These only keep for } 4 \\
\text { weeks after they're opened, OK? }\end{array}$ \\
\hline
\end{tabular}

Conjunctivitis

Apply 4 times a day, just pull 6 down the eye slightly, smear a small amount of ointment on to the gutter down there, blink a few times to disperse the ointment and then just try a touch onto where that stye seems to be, very gently. The idea is to try to put it onto the lid without touching it too much, because firstly, you might annoy the eye and secondly, you don't want to infect the ointment as well.

(Pharmacist demonstrates throughout the explanation.)

Antibiotic for dental patient
It's Amoxil, an antibiotic, he's6 given you, one to be taken three times a day. Once you start finish the whole course. It's probably best taken on an empty stomach, although it's not so important with this one exactly when you take it but you should avoid alcohol while you are taking it. 


\section{Table 16 The importance of pharmacists' situation-specific explaining (cont.)} behaviour

\begin{tabular}{|c|c|c|c|}
\hline $\begin{array}{l}\text { Explaining } \\
\text { Sub-skill }\end{array}$ & Situation & Description & $\begin{array}{l}\text { Modal Range } \\
\text { Rating (\%) }\end{array}$ \\
\hline
\end{tabular}
Cough If you take that from about 46
bottle (II) o'clock in the evening and 8 (53)
o'clock in the evening it means
if you wake up coughing you have another dose left; it works really well that way.

Put it in hot water and sip it. 6 That really soothes the cough.

That's your antibiotic there. If

Antibiotic for adult (I) you take them one 4 times a day and if you take them with or after your food because sometimes they can upset your stomach but if there's food in your stomach already it can minimise that.

b Directing

c Informing

\section{Antibiotic \\ for adult (II) \\ Cold symptoms}

Antibiotic for throat infection

Nasal
congestion
Complaining
patient

Antibiotic for dental patient
Two nasal sprays, use as directed; pain-killer, dissolve in water, and this pain-killer he takes 3 times a day with or after food.

You could have Beechams or 6 Lemsip, Beechams is also hot lemon, $O K$ ?

The only difference between 6 Beechams and the Lemsip is that Beechams just has paracetomol in it but the Lemsip has a decongestant as well.

Get her to take two for the first dose, sort of a loading dose to get it into her system quicker.

Do you want to buy Sudafed? 5 It's exactly the same drug only it's boxed already?

You should have received a little note saying that you were owed 40. It wouldn't possibly be in the bag because we have a record of it? But don't worry they will be in later on this afternoon.

Any pain-killer you can buy 5 will be suitable to take along (47) with this. 


\section{Table 16 The importance of pharmacists' situation-specific explaining (cont.) behaviour}

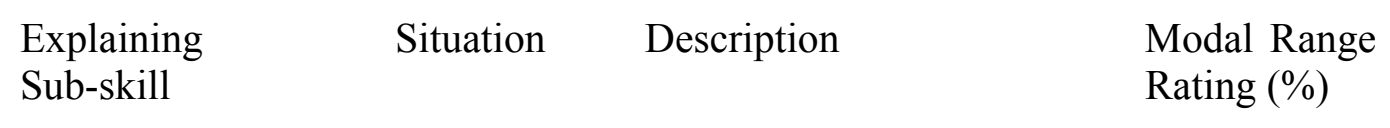

c Informing (cont.)

\begin{abstract}
Haemorrhoids
The Hemocane certainly is good and you'll see when you use it it is quite oily so it tends to help as a lubricant for the stools being passed.

The other thing that obviously eases them a lot is warm soapy water. Being very particular about cleansing them regularly, that helps to relieve the itch as well.

Holiday medication

Really Peter, the only way that you can avoid diarrhoea (73) is to be careful what you eat for the first few days until the body gets settled down to the sort of bacteria that is in the water there. Use bottled water for drinking and even brushing your teeth and avoid salads for the first few days.
\end{abstract}

Request for liquid paraffin

There are new EEC regulations out about liquid paraffin; that is the largest size that we're allowed to sell.

Request for You'd be wiser getting the liquid paraffin lactulose than liquid paraffin.(53)

Face spot Savlon would stop any skin 5 infection, I would leave it and let it take its course. I think that would be a safer thing to do. Just try and keep your hand away from it.

Throat Have you heard of a thing called medication Syndol. The reason I asked about did you feel a sort of vice gripping your head whenever you get it or a sensation of pressure is that it quite often indicates a tension headache. Like your brother, you seem to be trying lots of things and none of them seem to be working. If you want to try a small packet of Syndol and if that doesn't do the job, go to the doctor or optician.

Syndol actually has a sedative effect. It breaks the stress that brings on a headache. One of the problems is that it causes drowsiness. If you've any problems during the day or you've any sort of job where you might be impaired, you need to be careful. There's a 
small trial size.

\section{Table 16 The importance of pharmacists' situation-specific explaining (cont.) behaviour}

\begin{tabular}{|c|c|c|c|}
\hline $\begin{array}{l}\text { Explaining } \\
\text { Sub-skill }\end{array}$ & Situation & Description & $\begin{array}{l}\text { Modal Range } \\
\text { Rating }(\%)\end{array}$ \\
\hline
\end{tabular}

c Informing (cont.)

d Explaining for reassurance

\begin{abstract}
Antibiotic
\end{abstract}
for adult (I)

Patient: Can you drink alcohol with

these?

Pharmacist: I wouldn't.

Request for antibiotic (II)

To be honest with you, that's 6 what's doing it. Passive smoking is causing infections in children. That's unfortunately the way things are. We didn't know that until 4 or 5 years ago but it is a fact. You're smoking in a room, and children with the small size of lungs they have, that's causing it.

She's two so she's old enough. There should be no problem about giving UHT milk when on holiday.

Injured dog

Olive oil isn't sterile remember, so don't be applying it where (40) there's broken skin.

Calcium tablets would be difficult too because you're using adult tablets for people of human weight.

Pregnancy The test result takes about three test minutes to come through but it will seem like a long three minutes to you, OK?

Terminal Sometimes with cancer if 6 illness there's a lump it can be seen (40) more easily on an X-ray, but when these things are more diffuse, if it's all through, it may not show until it gets this big and I suspect that's what's happened. the attacks and go to the yoga it would be better than a lot of drugs.

Leg Its alright, but there is no need 


\section{Table 16 The importance of pharmacists' situation-specific explaining (cont.)}

behaviour

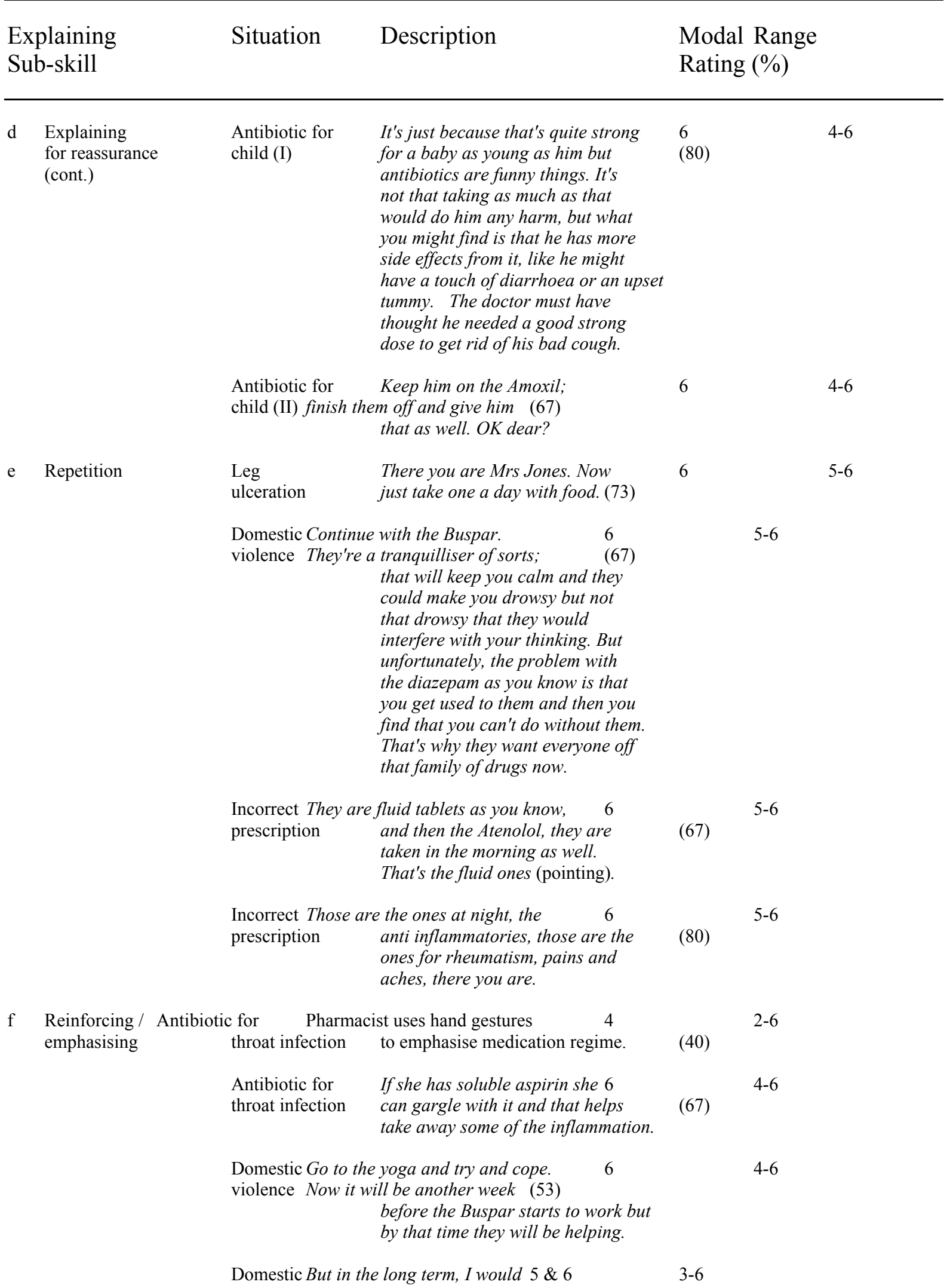


Table 17 The importance of pharmacists' situation-specific nonverbal behaviour

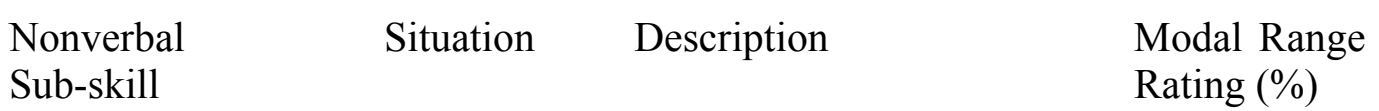

a Tone of voice Pregnancy test

$$
\begin{gathered}
\text { Pharmacist appropriately } \\
\text { lowers tone of voice thereby } \\
\text { demonstrating her sensitivity } \\
\text { to the need for confidentiality. }
\end{gathered}
$$

b Standing still Angina

Pharmacist by standing still 6 when patient is talking conveys concern.

$$
\begin{array}{ll}
\text { Conjunctivitis } & \begin{array}{l}
\text { Pharmacist listens to patient } \\
\text { by making good eye contact }
\end{array} \\
& \text { and standing still. }
\end{array}
$$

Leg ulceration Pharmacist standing still, faces towards patient, making eye (80) contact and appropriate vocalisations while patient talks about her leg.

c Eye Contact

$$
\begin{aligned}
& \text { Food } \\
& \text { supplement }
\end{aligned}
$$

Pharmacist appropriately maintains eye contact with customer, thereby conveying interest.

d Proximity

e Positioning

Pregnancy

test

Face spot Pharmacist, interested in

patient's condition, moves across counter to look at spot on patient's face.

By her appropriate close positioning to the patient the pharmacist demonstrates her sensitivity to the need for confidentiality.

\section{Leg}

Pharmacist moves forward

ulceration

when dispensing medication, (54) demonstrating interest.

Terminal Pharmacist's appropriate positioning in relation to customer indicates her willingness to listen. f Smiling and / Request for or nodding head
Pharmacist affirms patient 6 throughout by smiling and nodding head, thereby conveying a pleasant, cool and professional 
manner throughout the interaction.

g Using hand gestures
Domestic Pharmacist uses downward

violence hand gestures in trying to

calm anxious patient.
3-6 
Table 17 The importance of pharmacists' situation-specific (cont.) nonverbal behaviour

\begin{tabular}{|c|c|c|c|}
\hline $\begin{array}{l}\text { Nonverbal } \\
\text { Sub-skill }\end{array}$ & Situation & Description & $\begin{array}{l}\text { Modal Range } \\
\text { Rating (\%) }\end{array}$ \\
\hline
\end{tabular}

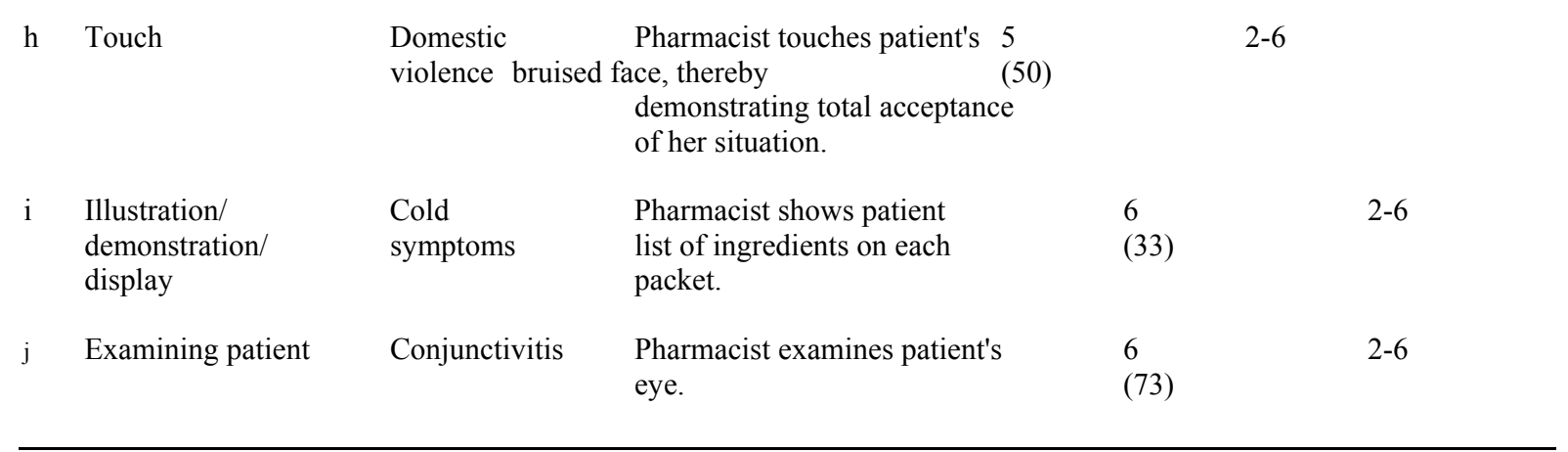




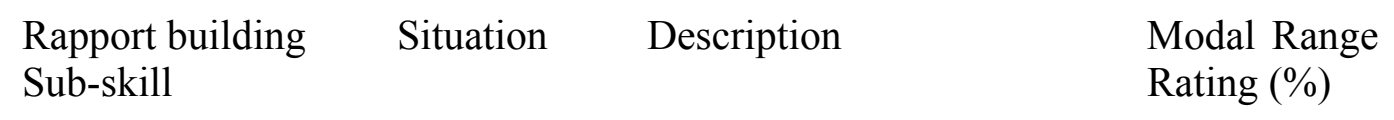

a Showing genuine concern
Leg
ulceration
Is it still not healing?

Oh dear!

(looking concerned).

Pharmacist standing still, faces towards patient, making eye (80) contact and appropriate vocalisations while patient talks about her leg.

Angina

That (patient's news) shatters 6 $m e !$

6

Pharmacist shows concern

for patient by giving her time.

Pharmacist shows interest in patient and refers to other (47) members of her family.

5

Domestic Pharmacist, by his orientation, $5 \& 6$ violence encourages interaction to continue.

Conjunctivitis

Pharmacist conveys interest 6 by going around counter towards patient.

Pharmacist examines patient's eye.

Well it's one of those things 6 you go through a period of being run down and it takes time to get built back up again.

Antibiotic for They're pretty painful things. 5 dental patient Isympathise with you.

Repeat angina My goodness, did you injure your prescription hand? Oh dear, I can fill in the rest for you, that's $O K$. $\begin{array}{ll}\text { Pregnancy } & \text { Pharmacist shows that they } 5 \\ \text { test } & \text { are genuinely pleased by smiling }\end{array}$ in response to the patient's positive test result.

Pharmacist smiling while

handing result slip to

patient - Congratulations!

Oh hello, Maire. 
Table 18 The importance of pharmacists' situation-specific rapport (cont.) building skills

\begin{tabular}{|c|c|c|}
\hline $\begin{array}{l}\text { Rapport building } \\
\text { Sub-skill }\end{array}$ & Situation & Description \\
\hline
\end{tabular}

d Being helpful Pregnancy

The test result takes about three minutes to come through, but it will seem like a long three minutes to you, OK?

$\begin{array}{ll}\begin{array}{l}\text { Nasal } \\ \text { congestion }\end{array} & \begin{array}{l}\text { Have you tried an inhalation at } \\ \text { all, sometimes it can help to take } \\ \text { a Karvol capsule or some Friar's } \\ \text { balsam put it into some boiling } \\ \text { water and inhale it. }\end{array} \\ \begin{array}{l}\text { Antibiotic for } \\ \text { dental patient }\end{array} & \begin{array}{l}\text { It's an antibiotic he's given you. } \\ \text { If you just hold on for a few } \\ \text { minutes I'll set it up for you. }\end{array} \\ \begin{array}{l}\text { Incorrect You just sign your name and } 5 \\ \text { prescription }\end{array} & \begin{array}{l}\text { I'll fill the rest in if you've } \\ \text { forgotten your glasses. }\end{array} \\ \begin{array}{l}\text { Request for } \\ \text { antibiotic (I) }\end{array} & \begin{array}{l}\text { Hold on a wee minute and I'll6 } \\ \text { phone and see if I can get } \\ \text { through to them. }\end{array}\end{array}$

Terminal Pharmacist accommodates customer's need to talk about (67) the diagnosis of his wife's bone cancer.

Accommodating
patient's needs illness

Nasal

congestion

I'm just out of Dequadin but 5 Bradesol or Strepsils or

Merocets would be very similar.

Complaining patient

Yes if you'd had 60 of one drug and 100 of another that would have thrown your whole system out.

Request for antibiotic (II)
She's happy enough; she's running around there; she's fairly interested in things; she's not a sick child. I'll make you up a cough bottle. Antibiotics are a waste of time. The difficulty would be that eventually resistance would build up so that in the future when she needs an antibiotic it would be a waste of time. 3-6

4 


\section{Table 18 The importance of pharmacists' situation-specific rapport (cont.) building skills}

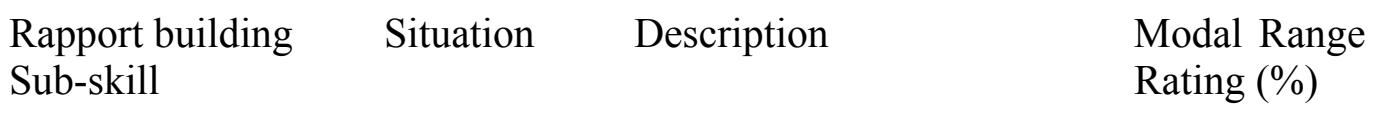

f Politeness in manner

\section{Complaining} patient
Patient: I had a prescription 6 made up here on Saturday,

there were two items on it. one was Moduretic and the other was, oh I don't know. There were a hundred of the other of each. Had it been the doctor's handwriting I would have said you had misread 100 for 60, but of course it was computer printed. So I wonder. could you check?

Pharmacist: Yes, of course, just one second.

$\begin{array}{ll}\text { Throat } & \text { I'm a wee bit worried when } \\ \text { medication } & \text { you say he's tried this and that } \\ & \text { it's not working. }\end{array}$

g Use of humour

h Being available / accessible

i Engaging

\section{Terminal Well when she's fit enough illness you clear off, there'll be a time when she needs you.}

Incorrect These fluid tablets, he's 6 prescription written 1 or 2 at night. Sure you'd be up all night. (laughs) I'll just change that for you.

Eye Drops

Pharmacist moves across counter to facilitate

Holiday Pharmacist comes around counter, thereby removing any physical barrier to interaction.

Food Pharmacist comes around counter, thereby removing any

supplement physical barrier to interaction.

Request for Pharmacist comes around counter, thereby making himself accessible to parent.

Repeat angina Pharmacist remains at counter prescription throughout, thereby making (53) himself available/accessible to patient. and normally I get a hundred explaining of use of eye drops. violence to need for confidentiality

Antibiotic for You've just been to the 6 
Table 18 The importance of pharmacists' situation-specific rapport (cont.) building skills

\begin{tabular}{|c|c|c|c|c|c|c|c|}
\hline \multicolumn{2}{|c|}{$\begin{array}{l}\text { Rapport building } \\
\text { Sub-skill }\end{array}$} & Situation & \multicolumn{2}{|l|}{ Description } & \multicolumn{3}{|c|}{$\begin{array}{l}\text { Modal Range } \\
\text { Rating (\%) }\end{array}$} \\
\hline $\mathrm{j}$ & Offering reassurance & Conjunctivitis & $\begin{array}{l}\text { I can give you an eye ointmer } \\
\text { that will quickly clear that up } \\
\text { Two days at the most should } \\
\text { it. If it doesn't seem to be goi } \\
\text { away in that time or if it seen } \\
\text { be getting worse get along an } \\
\text { have it seen to. I wouldn't thi } \\
\text { its anything more than that yc } \\
\text { know. }\end{array}$ & $\begin{array}{l}\text { nt } \\
\text { o. } \\
\text { do } \\
\text { ing } \\
\text { is to } \\
\text { nd } \\
\text { nk } \\
\text { ou }\end{array}$ & $\begin{array}{l}6 \\
(73)\end{array}$ & & $5-6$ \\
\hline \multirow[t]{4}{*}{$\mathrm{k}$} & $\begin{array}{l}\text { Preserving } \\
\text { confidentiality test }\end{array}$ & $\begin{array}{r}\text { Pregnancy } \\
\text { inter } \\
\text { male }\end{array}$ & $\begin{array}{l}\text { Pharmacist breaks off } \\
\text { on with female } \\
\text { patient in order to deal with } \\
\text { ient at the counter. }\end{array}$ & (53) & 6 & & $4-6$ \\
\hline & & & $\begin{array}{l}\text { Pharmacist demonstrates } \\
\text { her sensitivity to the need } \\
\text { for confidentiality by her } \\
\text { appropriate close positioning } \\
\text { in relation to the patient. }\end{array}$ & & $\begin{array}{l}6 \\
(67)\end{array}$ & & $4-6$ \\
\hline & & & $\begin{array}{l}\text { Pharmacist demonstrates } \\
\text { sensitivity to the need } \\
\text { for confidentiality by her } \\
\text { appropriate lowering of voice }\end{array}$ & & $\begin{array}{l}6 \\
(73)\end{array}$ & & $5-6$ \\
\hline & & $\begin{array}{l}\text { Domestic Pharı } \\
\text { violence apprc }\end{array}$ & $\begin{array}{l}\text { ist, responded } \\
\text { ately to patient's } \\
\text { quietness by closing down } \\
\text { space between them, thereby } \\
\text { facilitating interaction. }\end{array}$ & $\begin{array}{l}6 \\
(80)\end{array}$ & & $2-6$ & \\
\hline \multirow[t]{2}{*}{1} & $\begin{array}{l}\text { Showing } \\
\text { warmth }\end{array}$ & $\begin{array}{l}\text { Pregnancy } \\
\text { test }\end{array}$ & $\begin{array}{l}\text { Pharmacist shows that she } \\
\text { is genuinely pleased in } \\
\text { response to the patient's } \\
\text { positive test result. }\end{array}$ & & $\begin{array}{l}5 \\
(43)\end{array}$ & & $3-6$ \\
\hline & & $\begin{array}{l}\text { Domestic } \\
\text { violence bruis }\end{array}$ & $\begin{array}{l}\text { Pharmacist touches patient's } \\
\text { ace, thereby } \\
\text { demonstrating total acceptan } \\
\text { of her situation. }\end{array}$ & $\begin{array}{l}5 \& 6 \\
(36) \\
\text { ce }\end{array}$ & & $3-6$ & \\
\hline $\mathrm{m}$ & $\begin{array}{l}\text { Showing patient } \\
\text { interest }\end{array}$ & $\begin{array}{l}\text { Nasal } \\
\text { congestion }\end{array}$ & $\begin{array}{l}\text { Taking lots of time over } \\
\text { consultation. }\end{array}$ & & $\begin{array}{l}6 \\
(60)\end{array}$ & & $2-6$ \\
\hline
\end{tabular}


Table 19 The importance of pharmacists' situation-specific opening behaviour

\begin{tabular}{|c|}
\hline Opening \\
\hline
\end{tabular}

$\begin{array}{lll}\begin{array}{l}\text { Cold } \\ \text { symptoms }\end{array} & \text { Hello. (looking at patient) } \\ \begin{array}{l}\text { Complaining } \\ \text { patient }\end{array} & \text { Hello. (looking at patient) } \\ & & \\ \begin{array}{l}\text { Cough } \\ \text { bottle (I) }\end{array} & \text { Hello. (cheerfully) } & 5 \& 6 \\ & & (47)\end{array}$

5

6

(73)

Leg

Well Mrs Jones?

ulceration

6

$2-6$

Incorrect Good morning Mrs Moore,

prescription

are you well?

6

$5-6$

Terminal That's a great day John, how's

6

illness

things, is everybody well?

Holiday

How's the form Peter? Are you

medication

keeping alright? Good man. (53)

Repeat Hello Frank, how are you today?

(67)

angina

prescription

c Identifying patient

Antibiotic

Now, for Mr Smith.

6

for adult (II)

Now, for Brian Jones.

(40)

Antibiotic

for adult (I)

6

(40) 
Table 20 The importance of pharmacists' situation-specific closing behaviour

\begin{tabular}{|c|c|c|}
\hline $\begin{array}{l}\text { Closing } \\
\text { Sub-skill }\end{array}$ & Situation & Description \\
\hline
\end{tabular}

a Thanking patient

$$
\begin{array}{ll}
\text { Cold } & \text { That's £2.50 please...That's } 5 \\
\text { symptoms } & \text { great, thanks very much, } \\
\text { thank you. }
\end{array}
$$

Incorrect Thank you very much indeed. 6

There you are, alright?

b Initiating ending

Pregnancy Offers congratulations. Pharmacist shows that she

is pleased for patient.

Terminal Pharmacist's introduction the conversation as she walks in to dispense the prescription.
Request for Yes, getting the doctor out antibiotic (I) might be the best idea then he can sound your chest so that he knows exactly what's going on.

Antibiotic for Pharmacist aware of the child (II) mother's personal problems, (40) swiftly dispenses the prescription. 
Table 21 The importance of pharmacists' situation-specific suggesting/advising behaviour

$\begin{array}{lll}\text { Behaviour } & \text { Situation } \quad \text { Description } & \text { Modal Range } \\ & \text { Rating (\%) }\end{array}$

Suggesting/ Cold

Now well I think... you're not

6

4-6

Advising symptoms

taking any other medicines at

(67)

all? No well I think you'd be

better with the Lemsip if you're blocked up.

Nasal Have you tried an inhalation at

congestion all? Sometimes it can help to take a Karvol capsule or some Friar's balsam?

Put it into some boiling water and inhale it.

Domestic I would advise you to have a

5 violence go at the yoga.

Cough

I think you'd be better taking

bottle (I) the adult Meltus because it just

thins the phlegm and then you cough

it up yourself. The Covonia will

stop you coughing and it will

then just lie in your lungs.

If you're not improving by next week I think I would go down to the doctor.

If that doesn't ease it go back to your GP. There are stronger options that are prescription only.

Haemorrhoids

Request for liquid paraffin

You'd be wiser getting the lactulose than liquid paraffin.

Throat

Medication

Request for antibiotic (II)
What I'll do is give you a couple of day's supply of something to ease the pain of his sore throat, but if it doesn't clear up in say 48 hours get him to see the doctor.

She's two so she's old enough. There should be no problem about giving her UHT milk when you're on holiday. 
Table 22 The importance of pharmacists' situation-specific disclosing personal information behaviour

$\begin{array}{lll}\text { Behaviour Situation } & \text { Description } & \text { Modal Range } \\ & \text { Rating (\%) }\end{array}$

Disclosing personal information
I had a period 5 or 6 years ago when I had stye after stye after stye...I was totally run down and it took 2, 3, 4, 5, months to get back together again.

Antibiotic for dental patient
I must admit, I've suffered in the past from several abscesses. They've been very painful.
6 $2-6$
6

(40)
$3-6$

$(53)$
$6 \quad 3-6$


Table 23 The importance of pharmacists' situation-specific persuading behaviour

$\begin{array}{lll}\text { Behaviour Situation } \quad \text { Description } & \text { Modal Range } \\ & \text { Rating (\%) }\end{array}$

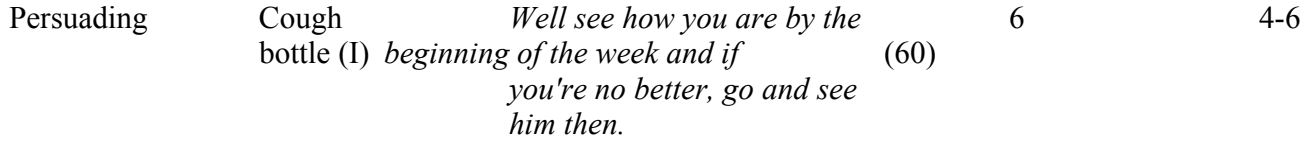


Table 24 Communication skills employed related to prescription dispensing activities

\begin{tabular}{|c|c|c|c|c|c|c|c|c|c|c|c|c|}
\hline $\begin{array}{l}\text { Prescription related } \\
\text { health issue }\end{array}$ & A & $\mathrm{B}$ & $\mathrm{C}$ & $\mathrm{D}$ & $\mathrm{E}$ & $\mathrm{F}$ & G & $\mathrm{H}$ & I & $\mathrm{J}$ & K & $\begin{array}{c}\text { Tota } \\
1\end{array}$ \\
\hline Leg ulceration & & 2 & & 3 & 2 & 2 & 1 & & & & & 10 \\
\hline Terminal illness & 1 & 2 & & 1 & 1 & 2 & 1 & 1 & & & & 9 \\
\hline $\begin{array}{l}\text { Complaining } \\
\text { patient }\end{array}$ & & & 2 & 1 & & 3 & 1 & & & & & 7 \\
\hline $\begin{array}{l}\text { Antibiotic for } \\
\text { throat infection }\end{array}$ & 1 & 1 & & 4 & & & & & & & & 6 \\
\hline Eye drops & & & & 1 & & 1 & & & & & & 2 \\
\hline $\begin{array}{ll}\text { Antibiotic for } \\
\text { dental patient }\end{array}$ & & & & 2 & & 3 & & & & 1 & & 6 \\
\hline $\begin{array}{l}\text { Incorrect } \\
\text { prescription details }\end{array}$ & 1 & & & 2 & & 3 & & 1 & & & & 7 \\
\hline $\begin{array}{l}\text { Antibiotic for child } \\
\text { I }\end{array}$ & 2 & & & 1 & & & & & & & & 3 \\
\hline $\begin{array}{l}\text { Antibiotic for } \\
\text { child II }\end{array}$ & 1 & & & 1 & & & & 1 & & & & 3 \\
\hline $\begin{array}{l}\text { Antibiotic for adult } \\
\text { I }\end{array}$ & & & & 2 & & & 1 & & & & & 3 \\
\hline $\begin{array}{l}\text { Antibiotic for } \\
\text { adult II }\end{array}$ & & & & 1 & & & 1 & & & & & 2 \\
\hline $\begin{array}{l}\text { Repeat prescription } \\
\text { for angina }\end{array}$ & & & & & & 2 & 1 & & & & & 3 \\
\hline Skill total & 6 & 5 & 2 & 19 & 3 & 16 & 6 & 3 & 0 & 1 & 0 & 61 \\
\hline
\end{tabular}

Key: $\mathrm{A}=$ Questioning $\mathrm{B}=$ Listening $\quad \mathrm{C}=$ Assertiveness $\quad \mathrm{D}=$ Explaining

$\mathrm{E}=$ Nonverbal communication $\quad \mathrm{F}=$ Building rapport $\quad \mathrm{G}=$ Opening $\mathrm{H}=$ Closing $\mathrm{I}=$ Suggesting/Advising $\mathrm{J}=$ Disclosing personal information $\mathrm{K}=$ Persuading 
Table 25 Communication skills employed related to non-prescription dispensing activities

\begin{tabular}{|c|c|c|c|c|c|c|c|c|c|c|c|c|}
\hline $\begin{array}{l}\text { Non-prescription } \\
\text { related health issue }\end{array}$ & A & B & $\mathrm{C}$ & $\mathrm{D}$ & $\mathrm{E}$ & $\mathrm{F}$ & $\mathrm{G}$ & $\mathrm{H}$ & $\mathrm{I}$ & $\mathrm{J}$ & K & $\begin{array}{c}\text { Tota } \\
1\end{array}$ \\
\hline Pregnancy testing & 3 & & & 1 & 2 & 7 & & 1 & & & & 14 \\
\hline Holiday medication & & & & 1 & & 2 & 1 & & & & & 4 \\
\hline Angina & & 3 & & & 1 & 4 & & 1 & & & & 9 \\
\hline Cold symptoms & 1 & & & 2 & 1 & & 1 & 1 & 1 & & & 7 \\
\hline Nasal congestion & & & & 3 & & 3 & & & 2 & & & 8 \\
\hline Cough medication I & 1 & & & & & & 1 & & 2 & & 1 & 5 \\
\hline $\begin{array}{l}\text { Cough } \\
\text { medication II }\end{array}$ & 1 & & & 2 & & & & & & & & 3 \\
\hline Conjunctivitis & 1 & 1 & & 1 & 1 & 4 & & & & 1 & & 9 \\
\hline Liquid paraffin & & 1 & & 2 & & & & & 1 & & & 4 \\
\hline Teething & 1 & & & & & & & & & & & 1 \\
\hline Food supplement & 1 & & & & 1 & 1 & & & & & & 3 \\
\hline $\begin{array}{l}\text { Request for } \\
\text { antibiotic I }\end{array}$ & 1 & & 1 & & 1 & 1 & & 1 & & & & 5 \\
\hline $\begin{array}{l}\text { Request for } \\
\text { antibiotic II }\end{array}$ & 2 & & & 2 & & 2 & & & 1 & & & 7 \\
\hline $\begin{array}{l}\text { Request for throat } \\
\text { medication }\end{array}$ & 2 & & & 2 & & 1 & 1 & & 1 & & & 7 \\
\hline Face spot & 1 & & & 1 & 1 & & & & & & & 3 \\
\hline Injured dog & & & & 2 & & & & & & & & 2 \\
\hline $\begin{array}{l}\text { Haemorrhoid } \\
\text { medication }\end{array}$ & 2 & 1 & & 2 & & & & & 1 & & & 6 \\
\hline Domestic violence & 1 & 1 & 1 & 4 & 2 & 4 & & & 1 & & & 14 \\
\hline Skill total & 18 & 7 & 2 & 25 & 9 & 29 & 4 & 4 & 10 & 1 & 1 & 111 \\
\hline
\end{tabular}

Key: $\mathrm{A}=$ Questioning $\mathrm{B}=$ Listening $\mathrm{C}=$ Assertiveness $\mathrm{D}=$ Explaining

$\mathrm{E}=$ Nonverbal communication $\quad \mathrm{F}=$ Building rapport $\quad \mathrm{G}=$ Opening $\mathrm{H}=$ Closing

$\mathrm{I}=$ Suggesting/Advising $\mathrm{J}=$ Disclosing personal information $\mathrm{K}=$ Persuading 


\section{Chapter 4: Discussion}

\section{Introduction}

The purpose of this research investigation was to employ a constitutive ethnographic approach to the identification of effective communication skills in community pharmacy practice. Few empirical studies have been conducted at the pharmacist-patient interface, in relation to the process of communication. In this sense, the present research initiative marks a milestone in the analysis of pharmacy practice.

However, identifying, interpreting and putting a value on behaviour is an extremely difficult task, particularly when the captured actions can be viewed from different perspectives. In this study the analysis was carried out by pharmacists themselves of their own behaviours in practice. To that extent it represents one view, nonetheless a centrally important one, in that these results are a summary of how the profession regards interpersonal skill. Indeed this was a key purpose of the study, to begin the process of pharmacists examining their 'communication' performance, as distinct from their 'clinical' performance, as it relates to diagnosis of disease, treatment and advice. Such a dichotomy is not always clear to the practitioner, in that what is communicated is usually seen as more important than how it is conveyed. This, therefore, makes analysis more difficult because either the difference is unappreciated or the emphasis is toward the content of the communication rather than its process. Where technical information is involved this problem becomes more marked.

There are, therefore, some considerations relating to the design of this research which should be borne in mind when evaluating the results. It is acknowledged that another type of expert knowledge omitted in this analysis of what constitutes effective pharmacist interpersonal skill, is that of the patient. However, the recruitment of patients would have affected the method for securing videotaped consultations, since it would of necessity have involved direct face-to-face contact between researchers and patients. This would not have been possible, given the agreement with study pharmacists to minimise interference and disruption for patients. Also, patient involvement in the fine-grained and time-consuming analyses inherent in this research would have been impossible within the two-year time scale of the project. Thus, it was not feasible to have those patients who appeared on the videotapes directly assess the pharmacists. At a general level, the views of members of the public concerning pharmacy services were obtained and these have been published elsewhere (Hargie et al., 1992). 
While the pharmacists' views were central to the investigation, it is, of course, important to recognise the value of the perceptions of patients involved in the consultations. This is for two reasons. Firstly, patients may support the observations of the practitioner, thereby providing collaborative evidence. Secondly, patients may dispute the pharmacists' view, and thus provide new information of which the practitioner was totally unaware or did not want to accept. Thus, where pharmacists rated a consultation ineffective, the patient may have found it acceptable, or vice versa, and so further research is required to ascertain the extent to which pharmacist and patient views about effective communication concur.

Another aspect of the nature of the analysis is also worth pointing out, that is, how would expert others (e.g. a behavioural scientist) have analysed the consultation? Here a different analysis base operates, in that the individual applies a systematised body of knowledge from which behaviours can be categorised. Thus, there can be differences between perspectives, all of which are 'right in their own eyes'. There were behavioural scientists centrally involved in the design and implementation of this study, and they played an important role at the stage of categorisation of behaviours. However, the ethnographic, consultative, methodology employed in the study meant that the views of the pharmacists were always central.

That the participating pharmacists did not come to the analysis as communication experts is therefore worth noting, particularly as their comments were not bound by behavioural science jargon or specific conceptual frameworks. For example, from an applied psychology standpoint (Dickson et al., 1989) it is important to :

(a) distinguish between the content of behaviour and its consequences;

(b) identify the relationship between skills and particular situations;

(c) measure the frequency of behaviours and their use as single or sequenced actions; and

(d) recognise covert and overt behaviours, that is those that can be outwardly observed and those that relate to our inward thoughts.

These aspects will be referred to later in an attempt to see if, or to what extent, pharmacists actually followed this analytical structure.

Having drawn attention to the perspective from which the analysis was made, it is also important to recognise the multiple peer review nature of the process. This facilitated a wide cross section of views undoubtedly reflecting both situational and personal factors (e.g. gender, experience, patient groups, practice context). Thus, at one level the results are a product of the variety of individual differences, and at another, the consensus achieved 
within each group. It is, however, recognised that the self-selection nature of the sample and the particular geographical location may have had an influence on the findings. Obviously, self-selection is the only way of conducting such research - it would neither be possible nor desirable to dragoon pharmacists into participation! With regard to the location of the study, it will be necessary to carry out similar work in other areas to ascertain the extent to which there may be peculiar regional variations in skill use.

The variety of experience and background of the pharmacy panel was important in that it meant that the issues raised in the analysis had to be thoroughly discussed, individual views challenged and substantiated or rejected, in order to arrive at a consensus. This consensus, therefore, can be thought as the 'truth' as seen from the group standpoint. Given that this was the manner in which the analysis took place, it gives added credibility to the results in that they may be regarded as a 'best fit' evaluation of communication performance in community pharmacy practice.

\section{Skill Categorisation}

In considering the 11 communication categories proposed by the study group, it is interesting to note the number of the sub-categories occurring under each, the nature of these and their allocated categories. For example, in three categories, suggesting/advising, disclosing personal information and persuading, no sub-categories were identified. Part of the reason is undoubtedly that in the latter two only three instances were reported, making micro analysis impossible.

In suggesting/advising 10 behaviours were identified, but no sub-divisions were made, even though it could be argued that there were, for example, different 'strengths' to the suggestion or advice,

e.g. $\quad$ "Have you tried an inhalation at all? Sometimes it can help to take a Karvol capsule or some Friar's Balsam."

or "What I'll do is give you a couple of days supply of something to ease the pain of his sore throat, but if it doesn't clear up in say 48 hours get him to see the doctor."

Each of these examples tends to be at opposite ends of the non-directive - directive continuum of advice giving. Similarly, other examples of suggesting/advising could have been categorised in terms of their influential nature: 
e.g. appealing to one's sense of good judgment - "You'll be wiser getting the lactulose than liquid paraffin."

or logical argument/reasoned explanation - "I think you'd be better taking the adult Meltus because it just thins the phlegm and then you cough it up yourself. The Covonia will stop you coughing and it (the phlegm) will then just lie in your lungs."

Several of the actual advisory comments made by pharmacists were also recorded under the explaining category as examples of 'informing'. Thus behaviours were not analysed in exclusive terms but seen from different standpoints. The exact reasons as to what prompted a particular decision are unknown but is is likely that the content/consequence aspect of behaviour analysis operated. This is further supported from the results in that while they suggest the discrimination of a single behaviour into multiple categories, they also demonstrate pharmacists distinguishing actions on a function or outcome basis. For example, reassurance is a sub-category of explaining, but is also a sub-category of rapport building. Interestingly, in this example, explaining is used to produce reassurance while providing reassurance is used to build rapport.

This leads to a further observation as to the nature of the sub-categories identified under the different main skills. Some are described by virtue of their verbal content (e.g. questions on symptoms, previous action taken, other medication used), while others were described in communication process terms (e.g. repetition, reinforcing, emphasising, politeness, use of humour, as well as nonverbal behaviours). Thus it may be argued that the different behaviours were seen either in communication 'content' terms or in communication 'construction' terms i.e. the what of communication and the how.

That some categories were sub-divided predominantly into one of either of these two dimensions is clear. For example, questioning was viewed as a content based skill, whereas explaining was much more a construction based skill. In the former case the emphasis was on the key questions to ask, no consideration being given to the notion of closed, open or leading questions (see Dickson et al., 1989). In the latter, various techniques were identified that would contribute to understanding. As for the other categories, listening, nonverbal communication and building rapport were more process oriented, while assertiveness, opening and closing tended toward the content orientation.

Interestingly, building rapport had by far the largest number of sub-categories. It may be postulated that the relationship element of practice is particularly powerful in that many 
strategies are employed to initiate, maintain and enhance relationships. Pharmacy is somewhat unique in that it operates as a helping profession within the realities of business practice (Morrow and Hargie, 1989). Thus there are two motivations for rapport with patients; one the demonstration of a caring practitioner, and second, the creation and preservation of patient loyalty to achieve business success.

\section{Levels of Skill Use}

It is perhaps not surprising to note that the level of positive skill use was greater in the episodes rated effective (Table 2) than in those classed as ineffective (Table 3 ) by a margin of over 2:1 (average 7.9 skills to 3.5 skills/episode). This observation adds weight to the internal consistency and validity of the results in that there would appear to be a direct relationship between communication effectiveness and frequency of skill use.

It must, however, be borne in mind that in several instances where the frequency of skill use was relatively high (i.e. 6 or 7), the episode was rated ineffective (Table 3), whereas up to this level of use was deemed effective in 8 episodes, and indeed in one effective consultation only two skills were identified. Thus, while generally a higher proportion of skill use occurs in effective consultations, such consultations can also be the product of less frequent, but judicious, application of communication skill. Equally, merely the more frequent use of a behaviour does not necessarily guarantee successful communication (Arkowitz, 1981).

When the profile of skills was examined in terms of the frequency of individual skill use in both effective and ineffective episodes (Table 4), a number of other factors emerged. In only one skill, that of questioning, was there an increased level of use in the ineffectively rated interactions. Where listening was concerned there was an 11-fold increase in the effective as opposed to ineffective consultations, suggesting that the ability to overtly listen is a key factor to effectiveness in community pharmacy. Similarly rapport building showed a fourfold increase, and the link between these two behaviours may be inferred. For example, the sub-categories under rapport building such as availability, showing interest and concern, helpfulness, referring to patients by name and recalling family circumstances are all indicative of listening behaviour.

In considering the nature of the episodes chosen as effective or ineffective, Table 3 indicates a higher preponderance of request type interactions and a total of six interactions where antibiotics were involved. The majority of these antibiotic situations involved a request for a medication which was not available without a doctor's prescription. Thus, while pharmacists 
could justifiably take a legal stand, the implication is that denial of help or inability to help is counterproductive to the interaction. How can satisfaction be given where the patient inevitably must be disappointed?

The two episodes where the frequency of skill use was most marked were the performance of a pregnancy test and conveying the results and dealing with a patient who had been the subject of domestic violence. In the former, 5 skill categories were identified of which rapport building predominated; in the latter a total of 7 skill categories was involved. Only in one other case, that of terminal illness were 7 skills used. What may be deduced from these results in that as the depth of the consultation increases, in terms of seriousness or confidentiality, so does the frequency and extent of skill use.

No particular patterns of skill use can be be inferred from the results, in terms of sequences of behaviour, although there is some evidence to suggest the situation specific nature of skill use. One particular example of this is demonstrated when comparing the level of skill used from prescription and non prescription related consultations. Here there was a slight increase from prescription to non prescription (5 skills/episode: 6 skills/episode). In the former, explaining and rapport building skills predominated; in the latter, rapport building, explaining, questioning and suggesting/advising.

It would, therefore, seem that, in general, non-prescription related consultations demand extended skill usage, with particular skills to the fore. It may be postulated that part of the reason for the differences is related to the fact that the patient has had a consultation with a doctor and therefore comes to the pharmacy better informed. In the other case the patient has taken the initiative to approach the pharmacist and therefore, with patients negotiating their own needs, the pharmacist may have to employ a wider repertoire of skills. Obviously, when responding to symptoms, questioning will be of major importance and its relatively high level of use (Table 25) supports this reasoning. Equally, it may be argued that in the prescription situation the doctor has given the advice/suggestion in the form of a written order, such that the pharmacist is not centrally involved. In the non-prescription situation however, the pharmacist plays a role equivalent to the doctor. The fact that there was a move from 0 to 10 in advisory behaviours in prescription as opposed to non prescription episodes is consistent with this observation.

\section{Individual Skills}


While the above comments relate to the broad spectrum of issues emanating from the data, it is important to examine more closely the individual categories of behaviour as identified by the pharmacist panel. Here it is helpful to look at each skill both in terms of its general importance and its relevance within specific contexts of practice.

What can be said at the outset is that the perceived import of a behaviour can be significantly different when judged in a general context as distinct from a specific context. Thus, the contextual or situation-specific nature of skill use is a vital determinant of any analysis. To this extent it may be said that situations alter cases.

\section{Questioning}

As has been stated, the analysis of questioning was predominantly at a content level, with questions being perceived as tools designed to uncover required pieces of factual information. This is consistent with pharmacist training in that the information gathering procedures are diagnostically oriented, where pharmacists are taught to follow clinical algorithms. Thus, the process is eliminative, the aim being to confirm or rule out preformulated diagnoses.

That there was a number of disparities between the general and specific situation (Tables 5 and 13) is, therefore, not unexpected, in that the perceived importance of information required is the dominating factor in determining the role of questions, and by extension whether the pharmacist asked for that information or not. This is seen in two different ways in that the general case may be highly rated but the specific case not so (e.g. other medication being taken?). Alternatively, the specific case may be crucial, but across the general range of situations the use of the skill is less so (e.g. exploring the situation in terminal illness and domestic violence).

It is also interesting to note that the content nature of questioning is pre-eminently taskoriented in focus. The emphasis is on the facts as distinct from the feelings or affective nature of questioning. Indeed, in the sub-category of showing interest where some affective questioning may have been expected to occur the questions relate to facts, although the question 'And what do you want it to be, positive or negative?' does get at the patient's feelings in respect of a potential pregnancy, and also lays a foundation for the pharmacist as to how to follow-up the consultation. Moreover, in the situations with heavy emotional appeal, terminal illness and domestic violence, the questions are factual in content. The fact that less than half of the pharmacist group judged showing interest by questioning as 
definitely important is indicative of a lack of appreciation of the feeling or emotional aspects of patient-centred practice.

In considering the range of questions asked in the specific situations, it is interesting to note that in the way the questions were structured, the vast majority required a Yes or No answer. While the pharmacists did not identify this feature, it does support the earlier observation of a diagnosis based on an eliminative clinical algorithm approach. To that extent it will work well provided all the issues are covered, but suffers from the major disadvantage that important or crucial information could be missed with potentially very serious consequences for the patient.

Against this background it will be important to undertake further research that will examine the style of questioning employed by pharmacists, particularly as it relates to how questions are phrased. Thus, there are crucial issues to resolve as to the balance between closed and open questions, the use of leading, probing and prompting questions, and the flow, pace and sequence of questions.

\section{Listening}

As with questioning, the perceived importance level of listening differed from the general to the specific situation (Tables 6 and 14). It may be argued that the listening skills employed spanned a continuum where listening was demonstrated to encourage the disclosure of further information, through positive interest in the patient's wider situation, to actively 'expressing' sympathy or empathy. Thus, there would appear to be gradations in the depth or extent of listening behaviour being displayed. Interestingly, it is at either end of this continuum that, in the general context, the importance values were highest. So listening for facts and listening for feelings are equally recognised as being crucial for effective interactions. However, the extent to which either or both takes place is less clear.

What is clear is that pharmacists have to make a conscious choice as to whether to listen or not. Examination of the specific contexts gives an indication of the various techniques identified as positive listening behaviours.

- $\quad$ body language (e.g. concerted eye contact, head nods)

- $\quad$ vocalisation

- $\quad$ use of questions to clarify statements

- $\quad$ allowing time for the patient. 
It should, therefore, be noted that listening as a skill employs the use of other skills i.e. questioning and nonverbal behaviour. To this extent it demonstrates the inter-related nature of communication skill and the goal-seeking and synchronised aspect of interpersonal communication where individual skills are combined to a common purpose.

\section{Assertiveness}

Although the ability to assert oneself is crucial to many interactions (Rakos, 1991), the general consensus from the study tends to indicate that the importance of assertiveness skills is not clear cut. This is demonstrated by the relatively low percentage values of the principal modal ratings and the range of 'importance' values (Table 7). However, the contextual influence was significant where the modal ratings increased with a more substantial vote and a narrowing of the range values (Table 15).

It may be suggested that pharmacists will move to an assertive position when forced to. However, in the retail context the maxim, 'the customer is always right' may be a very important determinant of any assertive action being contemplated. At the same time, from the examples given, pharmacists find themselves in situations where they have to stand up for their own rights. In this sense the rights may be personal, professional, or both. Thus, an unwillingness to infringe the law, even in the face of strong pressure to do so, would be a maintenance of professional conduct, possibly backed up with personal moral values.

\section{Explaining}

Because pharmacists are the last link in the prescribing chain, it is their responsibility to ensure that the correct medicine is dispensed and confirm that the patient knows how to take it correctly. Thus, it is not surprising that explaining as a function of practice is rated consistently highly across both the general and specific contexts (Tables 8 and 16). In the overwhelming majority of cases the predominant vote was for a modal 6 rating, thereby underlining the essential nature of explaining skills to community pharmacy practice.

It is interesting to note that within the sub-categories identified, the behaviours, in contrast to questioning skills, are more process oriented. Indeed, the process nature could be sub-divided to identify the predominantly functional aspects of explaining - instructing, directing, informing and reassuring as well as the technical dimensions - reasoning, repetition and reinforcing/emphasising, referred to earlier as the constructional elements in explaining. 
Thus, from the pharmacists' perspective the purpose of explaining and the procedures adopted are intrinsically linked.

Obviously in giving explanations information is imparted, so to that extent informing must be a part of every explanation. What is of interest in this analysis is the way in which pharmacists have identified and discriminated the categories of information transfer, from those where reasons are clearly given or not given, to those where the object is to reduce a patient's anxiety or give them confidence in their medication. In between is the sub-category of informing which has elements of the others, yet at the same time is relatively 'pressure' free, is often a response to questions, and in a number of cases overlaps with the suggesting/advising category.

Based on a frequency of skill use (Table 4), explaining clearly lies at the heart of pharmacy practice. Indeed, this informational and educational role is increasingly being recognised and will form part of a practice allowance payment for community pharmacists in the U.K. What will, therefore, be of paramount importance is that pharmacists develop and maintain the skills necessary to optimise their effectiveness in this role, and by extension the positive health benefits to patients.

Nonverbal behaviour

Nonverbal behaviour pervades all our interpersonal encounters (Knapp and Hall, 1992). It may, therefore, have been expected that it would have been the most widely recognised action, yet in fact only accounted for $7.5 \%$ of skill use (Table 4 ). In the majority of cases the function of nonverbal communication (NVC) was to convey interest and sensitivity, and as a complement to the verbal message (Table 17).

The relatively low frequency level of NVC identification may be explained from two points of view. On the one hand, it may be that pharmacists are familiar with the concept of body language, and therefore do not see it as a difficult or skilful part of their communicative repertoire. On the other hand, they may have failed to observe its use, by concentrating on the verbal messages being delivered. Either way there appears to be a low sensitivity to the nonverbal elements of interpersonal communication, yet their complementarity to the verbal message is crucial, if contradictory messages are to be avoided. It must, however, be pointed out that nonverbal elements of behaviour were recognised in other skill areas. For example, within listening nonverbal components played a central part. Thus, while nonverbal skills may not be recognised for their own intrinsic worth, they may be better understood and identified as they complement and support other skill use. 
Among those sub-categories listed under NVC (Table 9), that of illustration, demonstration and display stands out in that it is not merely the action of a part of the body like eye contact, but rather involves an object which is either displayed (e.g. patient information leaflet) or manipulated (medicine administration device). Yet, only one example of this was noted where the pharmacist used a medicine pack to draw the patient's attention to the ingredients.

The lack of illustration or demonstration and indeed its absence from the explaining category suggests that pharmacists perform poorly in this area. If this is indeed so, the reasons for it need to be uncovered in that illustration and demonstration are powerful tools in conveying understanding, particularly where parts of the body and administrative techniques are concerned. It may be tentatively suggested that lack of awareness of the available illustrative literature may be a problem, as well as the perceived time commitment to demonstrations. Yet it has been said that a picture is worth one thousand words and a demonstration worth one thousand pictures, so each has potentially time saving value, not to mention the improved understanding for the patient (Ley, 1988).

\section{Rapport building}

Reference has already been made to this element of pharmacist - patient communication in that it represents the largest single category in terms of frequency of use. Practitioner patient relationships are important in that when positively developed they engender patient confidence in the practitioner, promote mutual understanding, provide for trust and support, contribute to patient motivation and, in their ongoing nature, create a new platform for future encounters.

When examined, the rapport building sub-categories demonstrate a uniqueness in many of the issues raised. For example, preserving confidentiality is obviously part of the protective and trust building aspects of the relationship. Interestingly, among all the categories, it was the only one to score 6 by all of the survey group in the general context (Table 10), yet that unanimous vote was not repeated in the situation specific analysis (Table 18). This serves to reinforce the fact that situations alter cases even where they appear non-negotiable.

The empathic dimensions of the relationship are also clearly portrayed through the expressions of concern and showing warmth. Reference to the patient's name implies a prior knowledge of the individual or is used to create a more personal interaction - the first stage in building a relationship. Humour was used to overcome potentially difficult situations by dissipating a highly charged emotional interaction or possible conflict. Added to this was the 
obvious desire to meet patient needs through helpfulness, availability, demonstration of interest and the use of opportunities to give praise or reward.

Obviously in the business context pharmacists cannot ignore the importance of building rapport. It does, however, make certain demands, that of making oneself visible and accessible to the public, and providing sufficient time for interactions. In addition, knowledge of patients through the maintenance of patient medication records will contribute to the relationship as will the provision of private areas for more personal consultations. This latter observation raises the issue of how pharmacies are designed. Do they environmentally promote the relationship between the pharmacist and the patient or does the layout create the impression that this is merely just another shop where consumerism operates?

Despite the very positive endorsement of rapport building as a skill, it is also of interest to note that there may well be a level of lip service paid to this issue. Notice, for example, the very high score for showing genuine concern in Table 10, compared to the consistently lower scores for the same action in Table 18. This difference may be due to the discomfort professionals have with the more emotional aspects of practice (Dickson et al., 1989). The same pattern is repeated with accessibility/availability, to the extent that pharmacists may still continue to see their role in the dispensary as distinct from the shop floor area.

Against this background, there is considerable scope for pharmacists to undertake audits of, for example, how and where they spend their working day. For instance, what would it mean for an individual pharmacist if he/she was to increase the time spent in the shop floor by $10 \%$ ?

\section{Opening}

It may be suggested that opening is a particular facet of rapport building, in that it represents the first step in the process. Interestingly, two of the sub-categories involved greetings (Table 11), but where a name was used it was always accompanied by a question (Table 19). Such an action meant that there was inevitably some extension of the interaction. In the third category the concern was to identify the patient correctly, which was the most important element of opening as viewed by the study group.

However, this emphasis on safety was not carried through to the specific situation where patient identity was much less important than greeting. The question that recurs is what makes pharmacists depart from principles that they would hold firmly to (e.g. absolute preservation of confidentiality, identification of the correct patient)? Is it that they give a 
mechanical response to such questions, or restate what they believe they are, or what they should be, doing? Evidence from this study tends to contradict traditional thought and belief patterns of pharmaceutical practice, in that what may have been considered the 'official' pharmacy position may not actually hold true in practice.

\section{Closing}

Hargie et al. (1987) have suggested that effective closing may be achieved by the following methods:

1. Using closure indicators, thereby conveying to the patient that the interaction is about to end.

2. Summarising the interaction, thereby reminding the patient of the main points covered in the course of communication.

3. Obtaining feedback, thereby promoting clarity and mutual understanding.

4. Making future links with the patient.

5. Motivating the patient, perhaps by means of encouragement at the end of the interaction.

6. Reinforcing the patient, thereby promoting the patient's sense of achievement and facilitating future rapport.

7. Using non-task statements, thereby terminating the professional task-oriented interaction.

Examination of the examples of closing identified by the pharmacist panel (Table 20) indicate that closure indicators predominated as the technique used (e.g. 'That's £2.50'; turning/walking to dispensary). At the same time motivating the patient by encouraging a doctor consultation and giving praise were also used. However, the pharmacists tended to analyse closure behaviours in more global terms.

What may be said is that pharmacists did recognise closing as a skill area (Table 12), but had more difficulty defining the nature of the skill. This suggests that there is a knowledge deficit that needs to be addressed so that pharmacists know what to do and how to do it. 


\section{Suggesting/Advising}

Earlier reference was made to this particular activity in that no sub-categories were identified, but there was overlap with explaining behaviour. It is important to note that advising behaviour as defined by the pharmacist group only occurred in non-prescription related situations (Table 21). This points to a unique role where the pharmacist is viewed as the expert and consulted as such. In this regard, the use of personal pronouns to emphasise the pharmacist's opinion is quite marked (e.g. 'I would' 'I think'). Here the pharmacist assumes the patient's position to express what should be done.

Although the pharmacist panel defined suggesting/advising as the offer of personal/professional opinion as to a particular course of action, while simultaneously allowing the final decision to lie with the individual, the reality of the situation was that the statements made, by their construction, generally were more forceful or influential. For example:

\section{'I think you would be better with the Lemsip . . '}

'I think I would go down to the doctor...'

'I would advise you ...'

'You'd be wiser getting ....'

Having recognised the more directive elements of this behaviour, it may also be argued that patients consulting the pharmacist want definitive advice. So the medical model of health may be operative, that of handing over one's health to the professional to manage, rather than taking more individual responsibility.

Disclosing personal information

The question of how much of oneself the pharmacist gives to patients is also raised by this behaviour. Defined in terms of communicating personal information, the two examples identified both concerned the pharmacist sharing a common medical experience (Table 22). Such actions help to give the patient confidence in the pharmacist's knowledge, provide reassurance and facilitate patient self-expression.

Despite the possible virtues of this skill as a mean of facilitating the interaction and building rapport (Derlega and Berg, 1987), examination of the attitudes of pharmacists in response to 
disclosing personal information suggests that its therapeutic benefits are yet to be recognised by this group who may, therefore, be reluctant to utilise this strategy.

Persuading

From an intuitive standpoint, it may be expected that persuading would be a more integral part of practice, particularly since pharmacists are concerned to motivate or educate patients to use their medication correctly or manage their disease through appropriate lifestyle actions.

As a specific behaviour persuading was only identified on one occasion (Table 23), yet the reality was that in examining pharmacist statements and responses, many influencing techniques were used (e.g. reasoning, humour, use of the relationship, fear of untoward effects). This points to the fact that pharmacists do use influential strategies, but are largely unaware of these actions. Thus, as with closing, there is a need to educate pharmacists to what is now a widely researched skill area (Reardon, 1991), so that it can be used consciously to maximum benefit.

\section{Summary and Conclusion}

This study has sought to identify the core communication skills used by community pharmacists in their professional encounters with patients. In this way, it provides an important focus for training and further research. In relation to the former there are three main reasons why pharmacist training should include a strong communication component. Firstly, the interpersonal nature of the profession demands those skills which will lead to improved communicative performance. Secondly, and linked to this, is the ability to allow patients to negotiate their own needs and produce satisfaction. Thirdly, without a knowledge of the nature of interpersonal skill, pharmacists will not be able to evaluate their own or others communicative behaviour and performance. The range of skills and sub-skills charted in this research is of particular value in that it represents the first comprehensive, empirically validated, list of communication competencies which can be used to guide the content of CST programmes in pharmacy.

The research has also provided an insight into how pharmacists view their performance, especially those behaviours which are most crucial to practice, and their relative levels of frequency of use. The 11 core skills and 45 related sub-categories identified in this investigation (Table 1) provide a cartographic representation of the repertoire of skills 
employed by community pharmacists when interacting with patients. At the same time, it must be recognised that the frequencies identified are inevitably a product of the ability of pharmacists to recognise a particular behaviour. Thus, a low level of use does not necessarily imply less importance.

Given this, and based on a frequency of use pattern, building rapport, explaining and questioning emerged as the core skills adjudged to be central to pharmacy practice. Furthermore, the identification of the skill of suggesting/advising is worthy of note, since this is a dimension of communication which has not received any real attention in the health communication literature, and may indeed be a particular feature of community pharmacy practice.

Lack of a behavioural science background on the part of the pharmacy panel was also of positive benefit in this study in that it meant that the pharmacists were free to follow their own views unencumbered by prior communication schemas. Thus, the identification of areas such as rapport building and advising/suggesting as skill categories, while perhaps not necessarily unique to pharmacy, are unique in that they have been identified in this way. Certainly, as many medicines will move from Prescription Only Medicines to Pharmacy Only Medicines, the advisory role of the pharmacist will become more dominant, and the need for advisory skills (both clinical and interpersonal) more prominent.

While this research has produced valuable information, a number of key research questions remain to be answered following this novel initiative.

1. How do pharmacists construct questions when interviewing patients?

2. To what extent do pharmacists recognise and deal with the psychosocial aspects of practice?

3. Do prescription-related situations demand a different skill mix than non-prescription related interactions?

4. What situations in pharmacy demand assertive behaviour?

5. What situations in pharmacy call for special skills?

6. Do pharmacists use illustrations or demonstrations to promote understanding? 
7. How is practice to be developed to build rapport with the public?

8. How is practice changing traditionally held beliefs?

9. Is there a mismatch between actual practice and perceptions of practice?

10. What role does persuading play in practice?

One final issue to emerge is that of the situational factors implicit in the practice context. Here issues of time, environment, specific illness are important and further research needs to be carried out to determine the impact of these factors upon pharmacist-patient communication. Communication is, therefore, not merely about the study of what happens in face-to-face interaction since the context in which the interaction occurs will inevitably have an effect upon the behaviour of the participants.

In conclusion, this research can be regarded as a first step on the road to the discovery of exactly what constitutes effective communicative performance in pharmacy practice. The decisions in this study, as to exactly what were these communication elements, were all taken by pharmacists themselves and so the results represent an 'inside' view of practice. More work is needed to further the initial findings of this investigation within community practice and also to extend this process of discovery to encompass hospital pharmacy. The results of such research will enable appropriate adjustments to be made to current training and practice, thereby fully assuring the quality of service to patients. 


\section{Bibliography}

Anderson, R., Benelli, N. and Kimberlin, C. (1977) Use of video-taped feedback in training pharmacy students to take medication histories. American Journal of Pharmaceutical Education, 41, 49-53.

Arkowitz, H. (1981) The assessment of social skills. In: Behavioral Assessment. A Practical Handbook (eds. M. Hersen and A. Bellack). Pergamon Press, New York.

Armstrong, D. (1991) What do patients want? British Medical Journal, 303, 261-262.

Ascoine, F.J., James, M., Austin, S.J., and Shimp, L.A. (1980) Seniors and pharmacists improving the dialogue. American Pharmacy, NS20, 5, 30-32.

Balon, A. (1986) Counselling. Pharmaceutical Journal, 237, 452-454.

Beardsley, R. (1986) How to establish better communication links. U.S.Pharmacist, 56-57.

Becker, M. and Maiman, L. (1975) Sociobehavioural determinants of compliance with health and medical care recommendations. Medical Care, 13, 10-24.

Becker, M. and Maiman, L. (1980) Strategies for enhancing patient compliance. Journal of Community Health, 6, 113-35.

Becker, M. and Rosenstock, I. (1984) Compliance with medical advice. In: Health Care and Human Behaviour (eds. A. Steptoe and A. Mathews). Academic Press, London.

Benrimoj. S.I., Mitchell, I.B. and Wright., A.H. (1981) The development of a professional pharmacy course at the University of Queensland. Australian Journal of Pharmacy, 62, 876 877.

Berardo, D., Kimberlin, C. and Barnett, C.W. (1989) Observational research on patient education activities of community pharmacists. Journal of Social and Administrative Pharmacy, 6, 21-30. 
Berger, B. and Felkey B. (1989) A conceptual framework for focusing the teaching of communication skills and compliance-gaining strategies. American Journal of Pharmaceutical Education, 53, 259-265.

Brodie, D.C. (1982) Pharmaceutical education in perspective. American Journal of Pharmaceutical Education, 46, 274-280.

Brushwood, D.B. and Simonsmeier, L.M. (1988) Drug information for patients: part II: the pharmacist's legal duty. The Consultant Pharmacist, 3, 155-160.

Byrne, P.S. and Long, B.E. L. (1976) Doctors Talking To Patients. HMSO, London.

Campbell, W.H. (1981) Issues and priorities for research in geriatric pharmaceutical care. Drug Intelligence and Clinical Pharmacy, 15, 111 - 116.

Cassata, D. (1978) Health communication theory and research: an overview of the communication specialist interface. In: Communication Yearbook 2 (ed. B. Ruben). Transaction Books, New Jersey.

Caves, R. (1988) Consultative methods for extracting expert knowledge about professional competence. In: Professional Competence and Quality Assurance in the Caring Professions. (ed. R. Ellis). Croom Helm, London.

Chalmers, R.K. (1983) Chair report of the study on 'preparation of students for the realities of contemporary pharmacy practice'. American Journal of Pharmaceutical Education, 47, 393401.

Consumers' Association (1991) Pharmacists. How reliable are they? Which? Way to Health, December, 191-194.

Cooper, J.W. (1978) Drug therapy in the elderly: is it all it could be? American Pharmacy, NS18, 7, 25-26.

Department of Health and Social Security (1986) Primary Health Care: An Agenda For Discussion. HMSO, London.

Department of Health (1991) The Patients' Charter. HMSO, London. 
Derlega, V.J., and Berg, J.H. (1987) Self-disclosure: Theory, Research and Therapy. Plenum, New York.

Dichter Institute For Motivational Research Inc. (1973) Communicating The Value Of Comprehensive Pharmaceutical Services To The Consumer. American Pharmaceutical Association, Washington D. C.

Dickinson, J. (1987) Patient relations: the core of your practice. U.S. Pharmacist, 12, 28-30.

Dickson, D.A., Hargie, O.D.W. and Morrow, N.C. (1989) Communication Skills Training for Health Professionals: An Instructor's Handbook. Chapman and Hall, London.

Downs, C.W. (1988) Communication Audits. Scott/Foresman, Glenview, Illinois.

Du Vall, E. and Lash S.D. (1984) Counselling the oncology patient. Drug Intelligence and Clinical Pharmacy, 18, 743-745.

Eastwood, C.M. (1985) Nurse-patient communication skills in Northern Ireland - the educational problems. International Journal of Nursing Studies, 22, 99-104.

Ellis, A. and Beattie, G. (1986) The Psychology of Language and Communication. Weidenfeld and Nicholson, London.

Ellis, R. and Whittington, D. (1981) A Guide to Social Skill Training. Croom Helm, London.

Emmanuel M. (1985) Auditing communication practices. In: Inside Organisational Communication. (eds. C. Reuss and R. DiSilvas). Longman, London.

Enriquez, N. (1986) Post-script - don't forget to listen. Hospital Pharmacy, 21, 35.

Evison, R. and Veitch, G.B. (1985) Towards effective communication. Pharmaceutical Journal, 234, 833-836.

Faulkner, A. (ed.) (1984) Recent Advances In Nursing: 7 Communication. Churchill Livingstone, Edinburgh.

Finkelstein, N. (1981) Community pharmacy practice in the eighties. South African Pharmacy Journal, 48, 212-213. 
Fisher, C.M., Corrigan, O.I. and Henman, M.C. (1991) A study of community pharmacy practice (1. Pharmacists' work patterns). Journal of Social and Administrative Pharmacy, 8, $15-23$.

Fisher, D.J. and Morris, V.C. (1983) The gap between basic sciences and clinical pharmacy practice: is it epistemological? Drug Intelligence and Clinical Pharmacy, 17, 201-215.

Furnham, A. (1983) Social skills and dentistry. British Dental Journal, 154, 404-408.

Gahagan, J. (1984) Social Interaction and its Management. Methuen, London.

Gardner, M.E. and Mc Ghan, W.F. (1986) Objective assessment of interviewing skills: a comparison of two history types. American Journal of Pharmaceutical Education, 50, 165169.

Gardner, M.E., Trinca, C.E., Burpeau-DiGregorio, M. Y. and Stillman, P. L. (1983) The use of patient instructors to teach interviewing skills. American Journal of Pharmaceutical Education, 47, 56-59.

Goldhaber G. and Rogers D. (1979) Auditing Organizational Communication Systems: The International Communication Audit. Kendall Hunt, Texas.

Gossel, T. (1982) Improving patient communication. Australian Journal of Hospital Pharmacy, 12, 19-24.

Gravett, S. (1985) The pharmacist as a member of the patient care team. Hospital Material Management Quarterly, 6, 50-52.

Hanson, A. (1981) Use of standards of practice in the design and evaluation of a continuing education programme. American Journal of Pharmaceutical Education, 45, 56-60.

Hargie, O.D.W. (ed.) (1986) A Handbook Of Communication Skills. Croom Helm, London.

Hargie, O.D.W. (1992) Communication: Beyond the Crossroads. Monograph, Department of Communication, University of Ulster, Jordanstown. 
Hargie, O.D.W. and Morrow, N.C. (1986a) A survey of interpersonal skills teaching in pharmacy schools in the United Kingdom and Ireland. American Journal of Pharmaceutical Education, 50, 172-74.

Hargie, O.D.W. and Morrow, N.C. (1986b) Using videotape in communication skills training: a critical evaluation of the process of self-viewing. Medical Teacher, 8, 359-364.

Hargie, O.D.W., Morrow, N.C. and Woodman, C. (1992) Consumer perceptions of and attitudes to community pharmacy services. Pharmaceutical Journal, 249, 688-691.

Hargie, O.D.W., Saunders, C.Y.M. and Dickson, D.A. (1987) Social Skills in Interpersonal Communication. Routledge, London.

Jones, I. (1984) The teaching of communication skills - a personal view. Pharmaceutical Journal, 233, 640-641.

Kilwein, J. (1987) Reflections on the pharmacist-patient relationship. Journal of Clinical Pharmacy and Therapeutics, 12, 141-144.

Kitching, J. (1986) Communication and the community pharmacist. Pharmaceutical Journal, 237, 449-452.

Konsky, C. and Murdock, J. (1980) Interpersonal communication. In: Introduction to Speech Communication (eds. F. Cragan and D. Wright). Waveland Press, Illinois.

Korsch, B., Gozzi, E. and Francis, V. (1968) Gaps in doctor-patient communication: doctorpatient interaction and patient satisfaction. Paediatrics, 42, 855-71.

Knapp, M.L. and Hall, J.A. (1992) Nonverbal Communication in Human Interaction. Holt, Rinehart and Winston, New York.

Lamy, P.P. and Beardsley, R. (1982) The older adult and the pharmacist educator. American Pharmacy, NS22, 5, 40-43.

Laurier, C., Archambault, A. and Contandriopoulos, A. (1989) Communication of verbal information by community pharmacists. DICP, The Annals of Pharmacotherapy, 23, 862868. 
Leufkins, H.G.M. (1986) Patient counselling and the public image of the pharmacist. Pharmaceutish Weekblad, 121, 514-519.

Ley, P. (1977a) Psychological studies of doctor-patient communication. In: $\underline{\text { Contributions To }}$ Medical Psychology (ed. S. Rachman). Pergamon,Oxford.

Ley, P. (1977b) Communicating with the patient. In: Introductory Psychology (ed. J. Coleman). Routledge and Kegan Paul, London.

Ley, P. (1982) Satisfaction, compliance and communication. British Journal of Clinical Psychology, 21, 241-54.

Ley, P. (1988) Communicating With Patients. Croom Helm, London.

Lezberg, A.K., and Fedo, D.A. (1980) Communication skills and pharmacy education: a case study. American Journal of Pharmaceutical Education, 44, 257-259.

Love, D., Weise, H. and Parker, C. (1978) Continuing education in factors affecting communication: a novel approach. American Journal of Pharmaceutical Education, 42, 304307.

McCroskey, J. (1984) Communication competence: the elusive construct. In: Communication: A Multidisciplinary Approach (ed. R. Bostrom). Sage, Beverly Hills.

McKenzie, M. (1986) Communication skills for pharmacists. NARD Journal, 108, 69-73.

Maguire, P. (1984) Communication skills and patient care. In: Health Care and Human Behaviour (eds. A. Steptoe and A. Mathews). Academic Press, London.

Mija, T.S. (1980) Issue 1979 - bridging the gap between the basic sciences and clinical practice: teaching, research and service - a response from a dean. American Journal of Pharmaceutical Education, 44, 371-373.

Miller, E.R. (1981) Communication and the pharmacist. South African Pharmaceutical Journal, 48, 492-493.

Millis, J. (1975) Pharmacists For The Future: The Report Of The Study Commission On Pharmacy. Health Administration Press, Ann Arbor, Michigan. 
Millis, J.S. (1976) Looking ahead - the report of the Study Commission on pharmacy. American Journal of Hospital Pharmacy, 33, 134-138.

Minty, H. (1986) You and communication: aspects of behaviour. South African Pharmacy Journal, 53, 312-315.

Morrow, N.C. (1986) Communication as a Focus in Pharmacy Education and Practice. Ph.D. Thesis, The Queen's University of Belfast, Northern Ireland.

Morrow, N.C. and Hargie, O.D.W. (1985) Improving interpersonal communication in pharmacy practice. Pharmaceutical Journal, 235, 23-25.

Morrow, N.C. and Hargie, O.D.W. (1986) Communication as a focus in the continuing education of pharmacists. Studies In Higher Education, 11, 279-288.

Morrow, N.C. and Hargie, O.D.W. (1987a) Effectiveness of a communication skills training course in continuing pharmaceutical education in Northern Ireland: a longitudinal study. American Journal of Pharmaceutical Education, 51, 148-52.

Morrow, N.C. and Hargie, O.D.W. (1987b) An investigation of critical incidents in interpersonal communication in pharmacy practice. Journal of Social and Administrative Pharmacy, 4, 112-118.

Morrow, N.C. and Hargie, O.D.W. (1988) Pharmacist - Patient Communication. Royal Pharmaceutical Society of Great Britain, London.

Morrow, N.C. and Hargie, O.D.W. (1989) A new focus for CST: pharmacy practice as a helping relationship. Pharmaceutical Journal, 243, E16-18.

Morrow, N.C. and Hargie, O.D.W. (1992) Patient counselling: an investigation of core situations and difficulties in pharmacy practice. International Journal of Pharmacy Practice, $1,202-205$.

Morrow, N.C., Hargie, O.D.W. and Woodman, C. (1993) The advice-giving role of community pharmacists: a survey of consumer perceptions and attitudes. (In press).

Nuffield Committee of Inquiry (1986) Pharmacy. The Report of a Committee of Inquiry appointed by the Nuffield Foundation. The Nuffield Foundation, London. 
Okolo, E.N. and McReynolds, J. (1987) Counselling the terminally ill. American Pharmacy, NS27, 9, 37-40.

Pharmaceutical Society of Great Britain (1984) First report of the working party on pharmaceutical education and training. Pharmaceutical Journal, 232, 495-508.

Pharmaceutical Society of Northern Ireland (1990) Pharmacy Register. P.S.N.I., Belfast.

Pillow, W. and Schegel, J. (1981) Training future communicators. American Pharmacy, NS21, 43-45.

Portnoy, E. (1985) Enhancing communication with elderly patients. American Pharmacy, NS25, 8, 50-55.

Povey, T., Dunbar P.E. and Kendall, H.E. (1990) Pharmacist perceptions of the factors important to consumer loyalty. Pharmaceutical Journal, 245, R18.

Rakos, R. (1991) Assertive Behavior: Theory, Research and Training. Routledge, London.

Reardon, K. (1991) Persuasion in Practice. Sage, Beverly Hills..

Saunders, C. and Caves, R. (1986) An empirical approach to the identification of communication skills with reference to speech therapy. Journal of Further and Higher Education, 10, 29-44.

Simonsmeier, L.M. (1989) Topic update on: legal issues surrounding the pharmacist's duty to counsel patients, employment law and mail order pharmacy. American Journal of Pharmaceutical Education, 53, 73-77.

Skipper, M. (1992) Communication Processes and their Effectiveness in the Management and Treatment of Dysphagia. Ph.D. Thesis, University of Ulster, Jordanstown.

Smith, A. (1986) Recent developments in British pharmacy. Australian Journal of Pharmacy, 67, 692-698.

Smith, D.L. (1980) Knowledge + skills - apprehension = effective communication. Canadian Pharmaceutical Journal, 113, 255-258. 
Smith, F.J. (1992) A study of the advisory and health promotion activity of community pharmacists. Health Education Journal, 51, 68-71.

Smith, F. and Salkind, M.R. (1988) Counselling areas: views of community pharmacists and patients. Pharmaceutical Journal, 241, R7.

Smith, F., Salkind, M.R. and Jolly, B.C. (1990) Community pharmacy: a method of assessing quality of care. Social Science and Medicine, 31, 603-607.

Smith. V. and Bass, T. (1982) Communication for the Health Care Team. Harper and Row, London.

Smith, W.E. (1983) Clinical pharmacy in the 1980's. American Journal of Hospital Pharmacy, 40, 223-229.

Spitzberg, B. and Cupach, W. (1984) Interpersonal Communication Competence. Sage, Beverly Hills.

Stewart, M. and Roter, D. (eds.) (1989) Communicating With Medical Patients. Sage, Newbury Park.

Sumner, E.D., Dickinson, G.E., and Durand, R.P. (1987) Death education: a survey of U.S. colleges and schools of pharmacy. American Journal of Pharmaceutical Education, 51, 5356.

Tapster, J.V. (1987) Changing role of the community pharmacist. The Practitioner, 231, 1370, 2- 4.

Watts, J.G. (1989) Pharmacist communication techniques affect patient compliance. $\underline{\text { Palmetto }}$ Pharmacist, 28, 8-9.

Watzlawick, P., Beavin, J. and Jackson, D. (1967) Pragmatics of Human Communication. W.W. Norton, New York.

Weaver, L.C. (1980) A look to the future. American Pharmacy, NS 20, 24-26.

Whitney, H. (1988) Making words work. Journal of Pharmacy Technology, 4, 209-210. 
Wiemann, J. and Backlund, P. (1980) Current theory and research in communication competence. Review of Educational Research, 50, 185-199.

Williamson, V.K., Winn, S., Livingstone, C.R., Pugh, A.L.G. (1992) Public views on an extended role for community pharmacy. International Journal of Pharmacy Practice, 1, 223 229.

Wilson, M., Robinson, E.J. and Ellis, A. (1989) Studying communication between community pharmacists and their customers. Counselling Psychology Quarterly, 2, 367-380. 


\title{
Appendix 1: Introductory Leaflet Posted To Pharmacists In Greater Belfast.
}

\begin{abstract}
As well as providing details about the researchers, this Leaflet contained the following information.
\end{abstract}

Northern Ireland is to lead the way in responding to the challenge facing pharmacists and their profession. A joint initiative by the School of Pharmacy, Queen's University and the Department of Communication, University of Ulster has successfully secured major funding from the Leverhulme Trust for a two year project.

The challenge of the project is to identify what constitutes effective communication within pharmacy. The project will break new ground in its recording of pharmacy practice in situ. Using video, a range of consultations in community pharmacies will be recorded and analysed by pharmacists themselves.

The findings of the study will make a significant contribution to discovering the most effective methods of communicating with patients. The success of the project depends upon the involvement of local pharmacists. Your participation is therefore essential.

Becoming involved gives you an ideal opportunity

* To identify the best approaches for handling difficult patient consultations.

* To be part of a unique team of pharmacists sharing information and knowledge.

* To learn about the state of the art of effective communication techniques.

* To be at the forefront of pharmacy practice innovation.

If you would like more information about this project complete the attached cut-off slip and return it to the project officer. 


\section{Appendix 2a: Classification of Recorded Episodes}

\section{Instructions To Pharmacists}

During this individual viewing session we would like you to view each of your recorded episodes and broadly classify whether, in your opinion, your communication with patients was effective or ineffective, stating briefly the reason for your choice.

Format of individual viewing session record sheet

\begin{tabular}{ccc} 
Episode No. & Effective & Reason \\
\hline 1 & \\
\hline 2 \\
\hline 3 \\
\hline 5 \\
\hline 6 \\
\hline 7 \\
\hline 8 \\
\hline 9 \\
\hline 10 \\
\hline 11
\end{tabular}




\section{Appendix 2b: Selection of Effective/Ineffective Episodes}

\section{Instructions To Pharmacists}

During this individual viewing session you are requested to select the 10 episodes of your own communication with patients for further analysis by the study group. We would like you to select 5 episodes that in your opinion are examples of effective communication and 5 that you think are ineffective. Please complete the following details as fully as possible.

Name

Episode No.

What is the situation?

This is an example of effective/ineffective communication because

In my view, the communication in this situation is effective/ineffective because

I would consider this situation to be a rare occurrence

Yes [ ] No [ ]

I would deal with this situation

once a day [ ] once a week [ ] once a month [ ] once a year [ ] 


\section{Appendix 2b (cont.)}

Points to be borne in mind from the tape (not immediately obvious) when assessing the communication in this episode are:

What I would do differently to improve communication in this situation would be: 


\section{Appendix 3: Triad Selection of Core Episodes}

Now that everyone has completed Stage I of the project we are interested in generating some discussion about what constitutes effective and ineffective communication within community pharmacy practice. During this triad session we would like you to view your selected episodes again along with the 10 episodes from the other members of your group, and for the triad to select one effective and one ineffective episode per pharmacist. These will be included in the 'pool' of episodes that will be seen by the entire study group. We would like you as a triad to complete the 'selected' episode sheet provided so that at this session we have a completed viewing sheet for each of the 3 effective and 3 ineffective episodes selected by the triad. For the purpose of the exercise you should appoint a co-ordinator and secretary for each pharmacist.

For your 6 selected episodes please try to identify 7 different actions of the pharmacist which are, in your opinion, instances of effective pharmacist-patient communication. If this task seems rather abstract, make it more concrete by imagining that you have a pre-registration pharmacist beside you. Use the tape to point out to the inexperienced pharmacist instances of communication that they would do well to attend to. We would like you to describe what is going on in such a way that what you put on paper would be meaningful to someone who has not seen the videotape.

In column I we would like you to write down what the pharmacist did (actions) that, in your opinion, made the interaction either effective or ineffective. In column II we would like you to describe the message(s) that the action(s) listed conveyed (meaning). Finally, in column III we would like you to indicate whether the action was an example of ineffective or effective communication for both the pharmacist and the patient.

e.g. As a triad you might analyse the action described in the following way.
I. Action
II. Meaning
III. Effective(E) / Ineffective(I)

For the pharmacist For the patient

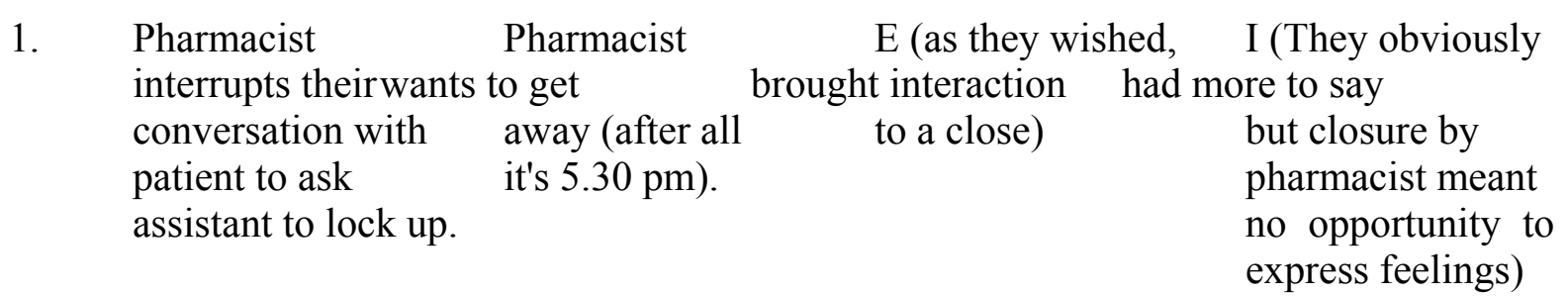

We appreciate that you may want to include more than one definition of the pharmacist's action and correspondingly, more than one meaning. However, having reached consensus 
within your triad we would like you to provide only one definition of every action and meaning in each episode. Please provide a minimum of 7 listed actions. 


\section{Appendix 3 (cont.)}

\section{Pharmacist - Patient Communication Project Triad Selected Episodes}

Pharmacist's Name

This episode was chosen as example of (please tick relevant boxes for each episode)
Episode No.

Effective communication (E) [ ] Ineffective communication (I) [ ]

The 7 actions which, in our opinion, are instances of good pharmacist-patient communication in this episode are as follows:
I. Action
II. Meaning
III. Effective(E) / Ineffective(I)

For the pharmacist For the patient

1.

2.

3.

4.

5.

6.

7. 


\section{Appendix 4: Agreed Definitions of Skills}

\section{Questioning}

The pharmacist's request for information to elicit specific information, diagnose specific symptoms and/or difficulties. To ascertain patient's knowledge and understanding, attitudes and opinions. Questions can be of various types and if inappropriately worded can have negative effects.

\section{Listening}

The process whereby the pharmacist receives and pays attention to the ideas and information from the patient's verbal and nonverbal responses.

\section{Assertiveness}

The pharmacist's skill of responding to patients in a manner which enables him or her to maintain and protect personal rights. This is achieved by the pharmacist clearly conveying his or her own ideas, beliefs and attitudes to the patient in a frank and forthright manner, while at the same time acknowledging and respecting the rights of the patient.

\section{Explaining}

The attempt by the pharmacist to provide the patient with information about a problem/situation to help promote patient understanding.

\section{Nonverbal}

Any communication between pharmacist and patient that does not involve speech.

\section{Building Rapport}

The on-going (and often deliberate) efforts of the pharmacist to establish 'a receptive atmosphere' which serves to put the patient at ease. This involves conveying a genuine sense of interest and respect, and generally facilitating pleasant social interaction.

\section{Opening}

The initial strategy used by the pharmacist to achieve a good social relationship with the patient.

\section{Closing}


The pharmacist's efforts to direct the patient's attention to the ending of the interaction and finally breaking the pharmacist-patient contact without making the patient feel rejected or shunned.

\section{Appendix 4 (cont.)}

\section{Suggesting / Advising}

The pharmacist's act of offering a personal/professional opinion to the patient about a particular course of action, while simultaneously allowing the final choice/decision to rest with the patient

\section{Disclosing Personal Information}

The pharmacist verbally communicating to the patient some personal information about him or herself.

\section{Persuading}

The pharmacist using various methods to influence the patient to pursue a recommended course of action. 


\section{Appendix 5: Consensus Group Work Sheet}

\section{Categorisations of 3 of the Behaviours from a Selected Effective Episode}

Pharmacist's Name

Episode No. 3

This episode was chosen as example of effective communication.

Effective/Ineffective (E/I)

Action

Meaning

$\overline{\text { For the pharmacist } \quad \text { For the patient }}$

1. Smiling and greeting patient by name
Makes everyone feel good and relaxed
E - Way of gaining patient's attention; establishes rapport; sets conducive scene
E - Conveys genuine interest

\section{Description}

Pharmacist smiles and greets patient by name, thereby encouraging a relaxed atmosphere, gaining patient's attention, establishing rapport, and showing genuine interest.

Categorisation $\quad 6 \mathrm{c}$ and $7 \mathrm{~b}$

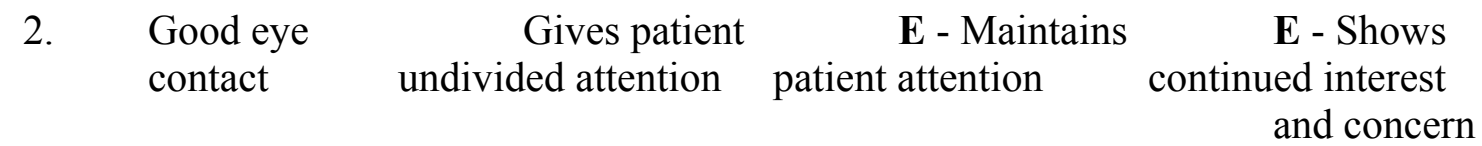

\section{Description}

Pharmacist, by maintaining eye contact, shows interest in, and concern for, the patient.

\section{Categorisation $\quad 2 \mathrm{a}$}

$\begin{array}{llll}\text { 3. Pharmacist } & \text { Lets patient see } & \mathbf{E} \text { - Conveys care } \\ \text { expressing } & \text { how the pharmacist } & \text { and concern for } & \text { Reinforces } \\ \text { dismay and } & \text { feels } & \text { the patient } & \text { personal interest } \\ \text { shock } & & & \end{array}$

\section{Description}

Pharmacist shows genuine interest, care and concern for the patient by stating that he is shocked by the news of the patient's ill health.

\section{Categorisation $\quad 6 a$}




\section{Appendix 6: Skill Categories and Sub-categories}

1.

\section{Questioning}

a

b

c

d

e

2.

a

b

c

3.

a

b

4.

a

b

c

d

e

f

5.

a

b

c

d

e

$\mathrm{f}$

Re: patient details, name, age etc.

Re: symptoms, previous action taken, cause of health problem, duration, lifestyle, previous action of other health professionals Checking out/exploring situation

Showing interest

Re: other medication being taken

\section{Listening}

Showing sympathy/empathy

Encouraging patient to provide information

Showing interest (beyond the problem)

\section{Assertiveness}

Enhancing credibility by referring to view of other health professionals

Pharmacist politely standing ground

\section{Explaining}

Reasoned instructions

Directing

Informing

Explaining for reassurance

Repetition

Reinforcing/emphasising

Nonverbal communication

Tone of voice

Standing still

Eye Contact

Proximity

Positioning

Smiling and/or nodding head 


$\begin{array}{ll}\mathrm{g} & \text { Using hand gestures } \\ \mathrm{h} & \text { Touch } \\ \mathrm{i} & \text { Illustration/demonstration/display } \\ \mathrm{j} & \text { Pharmacist examining patient }\end{array}$

\section{Appendix 6 (cont.)}

6.

b

c

d

e

f

g

$\mathrm{h}$

i

j

k

1

$\mathrm{m}$

7.

a

b

c

8.

a

b

c

9.

10.

11.

Persuading

Being helpful

Use of humour

Engaging

Opening

Closing

Polite closing

\section{Building Rapport}

Showing genuine concern

Showing pleasure/happiness

Greeting by name

Accommodating patient's needs

Politeness in manner

Being available/accessible

Offering reassurance

Preserving confidentiality

Showing warmth

Showing patient interest

Greeting, general

Greeting by name

Identifying patient by name (script check)

Thanking patient

Initiating ending of interaction

Suggesting/Advising

Disclosing personal information 


\section{Appendix 7: Situation Specific Analysis of Skills}

\section{Instructions to Pharmacists}

Now that you have the chance to view the tape in your own time we would like you to quickly watch through the episodes again. On the sheets provided you will find descriptions and categorisations of the various effective aspects of patient-pharmacist communication which you agreed to in the course of the group sessions. What we would like you to do is to indicate on the likert scale for each behaviour the extent to which you feel that the described behaviour is critical for effective pharmacist-patient communication in each particular episode.

For example, in the case of the pregnancy testing incident, you might feel that the pharmacist's action of building rapport by preserving confidentiality is essential for effective pharmacist-patient communication. If so you would circle the number 5 or 6 . On the other hand, if you feel that perhaps the pharmacist's building of rapport through preserving confidentiality is less than essential for effective pharmacist-patient communication in this situation, you might want to circle number 1,2 or 3 .

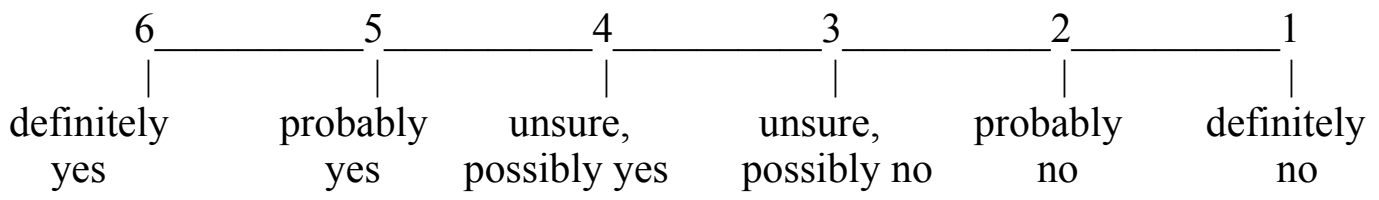

We suggest that you watch each episode and then complete the corresponding paperwork. As these scales will form the basis of the project data analysis, please be ensure that you complete all items by circling a number rather than simply marking the line. 


\section{Appendix 7 (cont.)}

\section{Ratings of 2 of the Behaviours from a Selected Effective Episode}

Pharmacist

Episode No. 5

\section{Description}

Pharmacist questioning patient about their symptoms, diet and previous treatment for haemorrhoids.

\section{Categorisation (1c)}

The pharmacist using fact finding questioning style when asking patient about their symptoms, diet and previous treatment for haemorrhoids.

\section{Rating (1c)}

In this particular situation, the pharmacist's action of using a fact finding questioning style when asking patient about their symptoms, diet and previous treatment for haemorrhoids, is essential for effective pharmacist-patient communication.

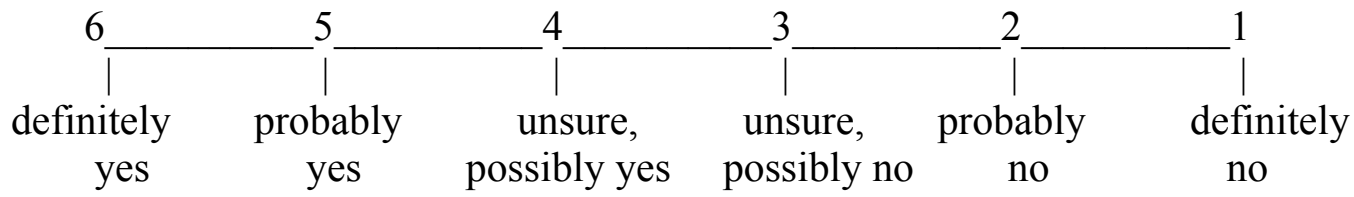

\section{Description}

Pharmacist explaining about product effectiveness and treatment options for haemorrhoids.

\section{Categorisation (4c)}

The pharmacist explains to the patient about the effectiveness of the treatment for haemorrhoids, informing her of the various options.

\section{Rating (4c)}

In this particular situation, the pharmacist's action of explaining to the patient about the effectiveness of the treatment for haemorrhoids, informing her of the various options, is essential for effective pharmacist-patient communication.

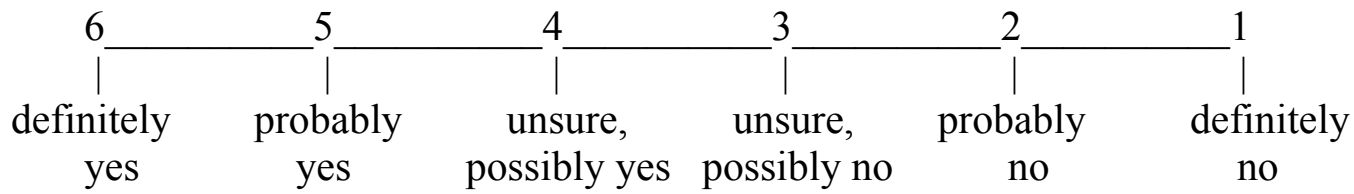




\section{Appendix 8: General Ratings of Skills}

\section{Instructions to Pharmacists}

Now that you have completed the rating scales for each of the specific episodes we would like you to complete the general rating scale. This time we are not interested in the importance of each of the behaviours in a particular situation but are wanting to know how important each of the listed behaviours are for effective pharmacist-patient communication in general.

We would like you to complete the rating scale for each of the sub-categories printed on the attached sheets. Please complete these in the same way as you completed the specific scales, remembering to circle the number that represents your opinion for all items.

\section{Example of General Rating Scale}

\section{$\underline{\text { Explaining Skills }}$}

\section{Reasoned instructions}

Are essential for effective pharmacist-patient communication.

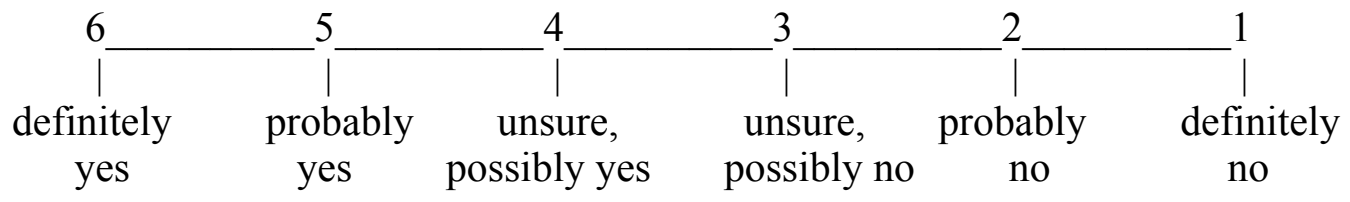

\section{b Directing}

Is essential for effective pharmacist-patient communication.

\begin{tabular}{|c|c|c|c|c|c|}
\hline 6 & 5 & 4 & 3 & 2 & 1 \\
\hline $\begin{array}{l}\text { efinitely } \\
\text { yes }\end{array}$ & $\begin{array}{c}\text { probably } \\
\text { yes }\end{array}$ & $\begin{array}{c}\text { unsure, } \\
\text { possibly yes }\end{array}$ & $\begin{array}{l}\text { unsure, } \\
\text { possibly no }\end{array}$ & $\begin{array}{c}\text { probably } \\
\text { no }\end{array}$ & $\begin{array}{c}\text { definitely } \\
\text { no }\end{array}$ \\
\hline
\end{tabular}

\section{c Informing}

Is essential for effective pharmacist-patient communication.

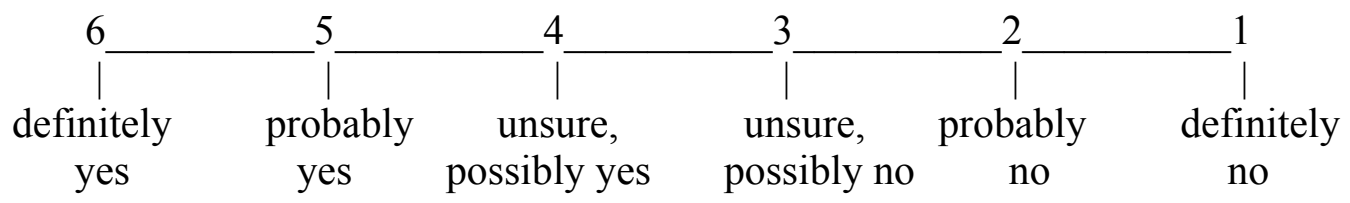




\section{Appendix 8 (cont.)}

\section{d Explaining for reassurance}

Is essential for effective pharmacist-patient communication.

\begin{tabular}{|c|c|c|c|c|c|}
\hline 6 & 5 & 4 & 3 & 2 & 1 \\
\hline $\begin{array}{l}\text { efinitely } \\
\text { yes }\end{array}$ & $\begin{array}{l}\text { probably } \\
\text { yes }\end{array}$ & $\begin{array}{c}\text { unsure, } \\
\text { possibly yes }\end{array}$ & $\begin{array}{l}\text { unsure, } \\
\text { possibly no }\end{array}$ & $\begin{array}{c}\text { probably } \\
\text { no }\end{array}$ & $\begin{array}{c}\text { definitely } \\
\text { no }\end{array}$ \\
\hline
\end{tabular}

\section{e Repetition}

Is essential for effective pharmacist-patient communication.

\begin{tabular}{|c|c|c|c|c|c|}
\hline 6 & 5 & 4 & 3 & 2 & 1 \\
\hline $\begin{array}{l}\text { efinitely } \\
\text { yes }\end{array}$ & $\begin{array}{l}\text { probably } \\
\text { yes }\end{array}$ & $\begin{array}{c}\text { unsure, } \\
\text { possibly yes }\end{array}$ & $\begin{array}{l}\text { unsure, } \\
\text { possibly no }\end{array}$ & $\begin{array}{c}\text { probably } \\
\text { no }\end{array}$ & $\begin{array}{c}\text { definitely } \\
\text { no }\end{array}$ \\
\hline
\end{tabular}

\section{f Reinforcing/emphasising}

Is essential for effective pharmacist-patient communication.

\begin{tabular}{|c|c|c|c|c|c|}
\hline 6 & 5 & 4 & 3 & 2 & 1 \\
\hline $\begin{array}{l}\text { efinitely } \\
\text { yes }\end{array}$ & $\begin{array}{c}\text { probably } \\
\text { yes }\end{array}$ & $\begin{array}{c}\text { unsure, } \\
\text { possibly yes }\end{array}$ & $\begin{array}{l}\text { unsure, } \\
\text { possibly no }\end{array}$ & $\begin{array}{c}\text { probably } \\
\text { no }\end{array}$ & $\begin{array}{c}\text { definitely } \\
\text { no }\end{array}$ \\
\hline
\end{tabular}

